\title{
Managing complexity: from visual perception to sustainable transitions-contributions of Brunswik's Theory of Probabilistic Functionalism
}

\author{
Roland W. Scholz ${ }^{1,2,3}$
}

Published online: 6 October 2017

(C) The Author(s) 2017. This article is an open access publication

\begin{abstract}
Coping with the multitude of information, relationships, and dynamics of the biotic and abiotic environment is a fundamental prerequisite for the survival of any organismic system. This paper discusses what contribution the Theory of Probabilistic Functionalism (TPF) of Egon Brunswik (1903-1955), which was originally developed for visual perception (including certain cognitive processes) and later for judgment, may provide today. The present paper elaborates that the principles of TPF go beyond the common weighting and regression analysisbased model of information processing that has been associated with the Brunswikian Lens Model. We argue that Brunswik's TPF rather provides basic principles of how organisms interact with complex environmental systems when processing cues (instead of information) and thus are able to produce evolutionarily stable representations of and judgments about the environment. TPF was formulated with no references to physiological processes. The present paper aims to demonstrate how well these principles correspond with current biophysical and neurophysiological findings, models, and simulations of sensation. We then discuss in what ways planning groups may be seen as organisms and how groups resemble and differ from (biological) organisms on the level of the individual and below. Based on this, we suggest how the principles of
\end{abstract}

Roland W. Scholz

roland.scholz@emeritus.ethz.ch

1 Department of Knowledge and Communication Management, Danube University of Krems, Krems an der Donau, Austria

2 Department of Environmental Systems Sciences, ETH Zurich, Zurich, Switzerland

3 Department of Psychology, University of Zurich, Zurich, Switzerland
TPF can be used to describe planning groups' activities when constructing planning variants or scenarios for sustainable transitioning. We illustrate the ways in which (under ideal constraints that may be provided in ideal transdisciplinary processes) planning groups follow principles such as vicarious mediation. Here, we reflect on the ways decision theoretic tools (such as Formative Scenario Analysis and Multi-Attribute Decision Analysis) can serve to construct robust (i.e., "evolutionarily stable") orientations for the future. It is difficult to validate big theories such as TPF. Thus, special attention is paid to the question of how strategies of validation (according to normal scientific principles) for different principles and TPF as such can be developed. We conclude that (in the context of sustainable transitioning) TPF can be utilized from a descriptive, prescriptive, and normative perspective. All three perspectives call for different strategies of validation.

Keywords Complexity · Probabilistic functionalism . Perception · Knowledge representation - Environment . Human-environment systems · Planning groups . Sustainability

\section{The Theory of Probabilistic Functionalism as a tool to investigate the relationship between human and environmental systems}

Egon Brunswik (1903-1955) was an outstanding psychologist of the mid-twentieth century. As a scholar of the physicist Moritz Schlick (1882-1936) and the psychologist Karl Bühler (1879-1963), he was associated with the Vienna Circle (Uebel 2011). His Theory of Probabilistic Functionalism (Brunswik 1952) provides a groundbreaking approach to decision research and cognitive science from 
both a conceptual and a methodological perspective. As expressed by the title of his first English-language paper co-authored with E. C. Tolman, The Organism and the Causal Texture of the Environment (Tolman and Brunswik 1935), Brunswik was interested in how the human perceptual and cognitive system was acquiring and processing the myriad of environmental information and its complexity.

Much of the reception of Brunswik's work referred to judgment under uncertainty and his well-known Lens Model. Brunswik suggested that correlational relationships reasonably represent the "psychological mechanism" of information processing for tasks in which a subject has to integrate different cues of an object (Brunswik 1956). This promoted the application of the linear model and-todaymany applications of the Lens Model refer to regression analysis in the field of social judgment research (Karelaia and Hogarth 2008). However, Brunswik considered the Lens Model rather as a didactic device to demonstrate the TPF as the essence of his Conceptual Framework of Psychology (Brunswik 1952).

Brunswik's research was dedicated to the question of how an organism-given a myriad of information and overly limited capabilities to sense and process information-is able to generate a sufficiently adequate and accurate representation of its complex environment. Brunswik's work is also of interest from a complexity perspective, as he elaborated that the uncertainty that an organism is facing when interacting with the environment is due to the "equivocality (Mehrdeutigkeit) in the environmental causal couplings" (Tolman and Brunswik 1935, p. 44).

Brunswik adopted a cognitive, system-theoretic perspective. The biophysical and physiological processes underlying sensation remained rather unspecified and in the background. When referring to the principle of "intersubstitutability of certain activities, habits, sense departments, or organs" (Brunswik 1952, p. 18), he considered perception, the formation of opinions or actions, as a complex, multilayered process (such as processes in the environment). Stimulated by Heider's distinction between thing and medium (Heider 1920; Radler 2015), he acknowledged that there is no mechanistic one-to-one process between biophysical sensation and perception and subsequent cognizing, deciding, and acting. The principles of TPF presented in this paper describe how organisms acquire, evaluate, and process information from external stimuli. This includes social judgment theory, a "direct legacy from Brunswik," which was developed in the 1970s (Hammond et al. 1975).

This paper goes beyond the application of TPF to describe judgment and decision making on the level of the human individual and of a group. The group perspective has already been suggested by Brunswik (1955, p. 198) and was developed later by various researchers (see Adelman et al. 2003; Birnbaum et al. 1976; Brehmer and Hagafors 1986; Rohrbaugh 1979). The present paper extends this perspective to consider teams that deal with sustainable transitioning of environmental systems such as cities or rural systems. This is done based on a definition of organisms as functional, adaptive units that allows us to conceive groups as organisms (see Sect. 4 and Wilson and Sober 1989, 1994, 1998). We further discuss the fundamental contribution that TPF may provide for the upcoming research on coupled human-environment systems (Binder et al. 2013; Liu et al. 2007a, b; Scholz 2011; Seidl et al. 2013) in the new field or discipline of sustainability science(s).

To do this, we first present the basic ideas and epistemological assumptions of TPF. These ideas were already outlined in Brunswik's Habilitationsschrift (habilitation thesis) Psychology as a Science of Objective Relations (Brunswik 1937). One of the groundbreaking ideas in this thesis was that psychologists have to construct a model of the individual's environment (in which perception or action takes place) before they can meaningfully construct models of the psychological processes, as perception is fundamentally linked to and mediated by what humans are accustomed to perceiving.

Brunswik demonstrated his theoretical ideas mostly by discussing the visual-perceptual system. His favorite paradigm was "body-size constancy" (Brunswik 1937, p. 228), i.e., the phenomenon that bodies "fairly retain a constant size ... under normal conditions." Body-size constancy, which he generalized to "thing-constancy", (Brunswik 1940) or object-constancy (Tolman 1956), is considered to be "a fairly reliable, deep-rooted, wellestablished, broadly supported habit of the perceptual system." The perceived size and shape of the body will mostly remain constant, even if the physical, stimulusbased "retinal representation" becomes distorted. "This effect is of extreme biological importance to the organism, since otherwise no orderly and self-consistent 'world' of remote manipulable 'independents' could be established; the physical and topographical constants of the environment would be completely lost in the random variations of their 'proximal stimulus representations.' No things could be recognized as identical, when looked [at] under changed circumstances ..." (all quotes from Brunswik 1937, pp. 228-230, here the relation of an object to the givens, i.e., its constraints of appearance is stressed; see Fig. 1). Here, Brunswik stresses "meaningful representations by signs ..." and states that "the intercourse of the organism with its environment takes place in the formation of signGestalten," a concept discussed in Tolman's paper on Purposive Behavior in Animals and Men (Tolman 1933). 
Fig. 1 The context and "cues of the circumstances" are taken into account when processing specific cues on size constancy
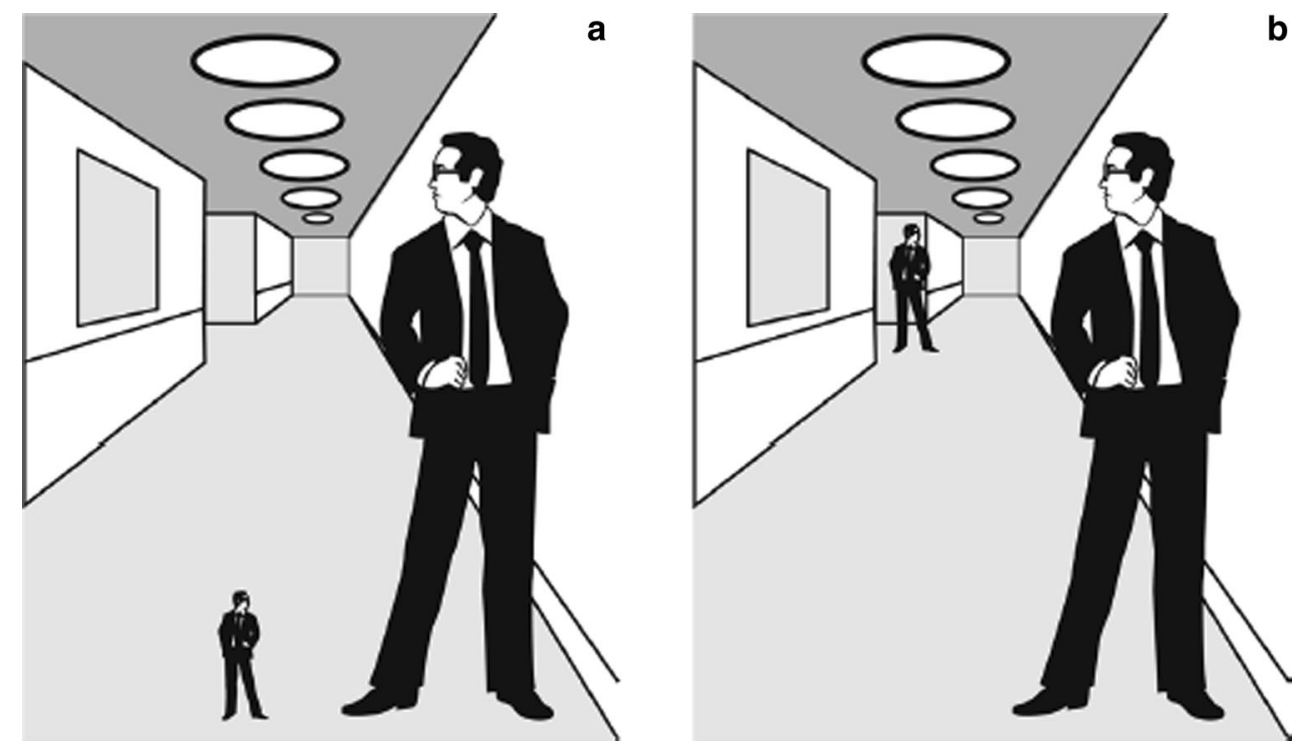

Thus, it is not information but cues that are the basic units of perception.

The idea behind functionalism is that the organism is facing an abundance of physical stimuli that cause "randomly diverging effects" (p. 232) on the cues or traits that are perceived. A challenge of the cognitive system is to extract the "behaviorally important physical traits" (p. 232). This is well illustrated in Fig. 1. The elliptical circles are usually judged as being ceiling lights of the same magnitude, even though the representation of activation differs. The same holds true for the two men shown in Fig. 1b. But this is not the case for those in 1a, as there are no human beings (with the same proportions of bodily parts) in the natural environment with this size difference. The developed human perceptual system is prepared to extract those "cues of the circumstances" (Umstandskriterien; p. 233) that provide a robust, reliable, and valid representation of the environment. Here, we encounter the laws of vicarious mediation and vicarious functioning, which mean that the perception and processing of cues are affected by other cues. "Organisms have learned to use a large variety of cues in a vicarious manner, especially where a certain life-important type of fact is functionally difficult to attain ..." (p. 233). The organism is building functional "constant couplings" (p. 232) to create a set of salient cues that sufficiently represent the environment. This quote also reveals the functional perspective in Brunswik's TPF.

Figure 1 may also be taken to illustrate the genuine ambiguity of distal stimuli or cues. The perceptual system is embedding specific ambiguous and misleading proximal cues and relating them to other cues to construct stable percepts. This may be called macromediation (Goldstein 2006) and must be distinguished from micromediation, which refers to more specific properties of a cue (e.g., the small man is the same size as the large man). Here, Brunswik metaphorically differentiates between a molar and a molecular level of perception and mediation and leaves no doubt that macromediation, i.e., the understanding of which of the perceived cues of the memory are used for functional achievement, is the core subject matter of psychology.

We should note that the concept of cue is used similarly to the concept of sign, which is (a cluster of) information that has some notion or meaning, as it informs about properties and states of the environment. These ideas are elaborated in Brunswik's paper, Psychology in Terms of Objects (Brunswik 1937), which reveals his constructivistmaterialist view: not the stimuli, but the processing of certain cues taken from the environment, form perception.

For Brunswik, "Psychology deals with the abilities of organisms to establish intercourse in a successful way with the surrounding world, on reception (cognition) as well as in action" (Brunswik 1937, p. 236). Here, the term world means "his world," the "Umwelt" [in English, the environment] "to borrow this term from Uexküll" (p. 237). We can see how close Brunswik has been to the cradle of environmental sciences, as Jakob von Uexküll was the founder of the first environmental institute at a university (von Uexküll 1987).

We consider Brunswik's TPF to be a comprehensive, highly consistent theoretical approach to how human systems efficiently select and process cues from an abundance of information that are sufficient for building a cognitive representation for successfully interacting with the environment. The term probabilistic in TPF acknowledges that, in practice, we may almost never face unequivocal information or cues. A probabilistic nature is ascribed to both 
the acquisition and sampling of cues (what exact information we get depends on an infinity of "stray causes") and to the processing of these cues. Here, the principle of vicarious mediation or vicarious functioning of information describes how the organism copes with the ambiguity of environmental information. We can illustrate this easily when we think about an interview. The wording or answers an interviewee provides depend on a multitude of constraints (e.g., on unexpected disturbances), and when the interviewer interprets the words or phrasings, they may have no unequivocal meaning, requiring the interviewer to use proxies for understanding.

For approximately 25 years, the author of this paper has used TPF as a reference framework for describing and conceptualizing knowledge integration, planning processes, and mutual learning among science and practice (i.e., transdisciplinary processes) when dealing with complex, ill-defined environmental problems such as regional transitions toward sustainable development (Scholz et al. 2006; Scholz and Steiner 2015a; Scholz and Tietje 1996, 2002). Based on this experience, we argue that from ontological, epistemological, and functionalist perspectives, the principles of TPF can be well applied and utilized to better understand these processes. To illustrate, in the next section, we present the principles of TPF that Brunswik laid out in a systematic research program and a coherent set of papers (The Brunswikian Society 2015). The reader can also find extensive discussions of TPF in the writings of Hammond and Stewart (2001), Gigerenzer and Murray (1987), Wolf (1995), Fischer and Stadler (1997), Goldstein and Hogarth (1997), Doherty and Tweney (2004), or Kirlik (2006b). Section 3 shows how the principles of the perceptual-cognitive TPF correspond to patterns of biophysical processes of visual perception in the light of contemporary theories of sensation. Section 4 demonstrates and discusses whether and how TPF's principles can serve to describe and structure planning groups' processes of representing, projecting, and evaluating complex real-world cases when supporting sustainable transitioning (Scholz et al. 2006). As TPF may be considered a framework (as Brunswik conveyed in the title of his main book) or metatheory rather than a theory, Sect. 4 discusses the question of validation, and the discussion and conclusion deal with an appraisal of TPF from a contemporary decision, complexity, and sustainability theory perspective.

\section{The basic principles of probabilistic functionalism}

Much about TPF is explained in "Introduction." In general, TPF focuses on coupled human-environment systems from a functionalist, Darwinian perspective. The human system has to adapt to the environment when facing reducible and irreducible uncertainty in an equivocal environment. However, humans can also change the environment by "different classes of means-objects as leading to certain classes of goals" (Tolman et al. 1958) to meet their needs. Next, we present Brunswik's main basic statements in the form of principles.

\subsection{An adaptive functionalist perspective (P1)}

Brunswik's position is that, for acting or adapting appropriately to the environment, the individual must fight through the environmental information to sufficiently secure his or her survival (Brunswik 1943). He was talking about organisms when taking a broad perspective of rats' learning in experimental settings (Brunswik 1939) and organismic and human perception, as well as human judgments, cognition, and action. Thus, the process of perception has to be understood from an adaptation perspective since it has impacts on subsequent related actions.

\subsection{A dualist human-environment perspective (P2)}

For Brunswik, the "organism and environment appear as equal partners" (Brunswik 1957, p. 41) and can therefore be viewed as inextricably coupled organism/human-environment systems. By physical environment, we mean the "geographical" (material, biophysical) surroundings as well as the stages along the "historic" axis of the organism, that is to say, its past and future (Brunswik 1943, p. 255). Thus, the environment is restricted to the tangible environment of the past and the future. The dualist perspective is expressed pronouncedly by: "Both organism and environment, ... each with properties of its own: psychology must be concerned with the texture of the organism or of its nervous properties and must investigate them in depth; it also must be concerned with the texture of the environment" (Brunswik 1952, p. 20).

To strengthen the dualist view, we may say that human and environmental systems are conceived as inextricably coupled (Scholz 2011). This implies (together with the functionalist perspective, $\mathrm{P} 1$, and the probabilistic nature of cues) that the perceptual process can only be understood when being conceptualized within a systemic perspective that encompasses the human organism and its environment (Brunswik 1933, 1936). 
In the following, we posit that the dualist perspective of human and environmental systems and other principles of TPF also hold true for human systems above the individual, such as planning teams or companies. To do this, the present author defines a human individual as all the activities of all living cells that emerge from the zygote and their interactions. The environment of the individual comprises the atoms of the universe minus the atoms of the living cells. Based on this, higher human systems, such as groups or organizations, may be defined as the cell activities of those individuals' actions that may be assigned to the group or organization. The environment of a group, for instance, can then be defined simply as the atoms of the universe minus the activities of the atoms of the cells that were at work for those activities of the members of a group that are assigned to the group's activities. This definition also allows us to define a cell-based material-biophysical layer and an information and cognitive (mind)-based layer of any human system (Scholz 2011). We think that this double complementarity meets the basic ideas of TPF. Brunswik presumably shared this double dualist perspective, at least from a theory of science perspective. However, he was stressing the primacy of the mind in philosophical dualism and looked skeptically at simplified (material) biophysical, sensation-based approaches as well as idealistic, subjectivistic, and mentalistic ones.

\subsection{Probabilistic information acquisition and processing (P3)}

Brunswik was dealing with uncertainties in both the environment and the human system (expressed by the phrase "stray causes" in Fig. 2): We are facing "environmental ambiguity, no matter how smoothly the organismic instruments and mechanism may function ... at least as far as ... relevant more distal regions of the environment are concerned" (Brunswik 1943, pp. 258-259). Furthermore, Brunswik hypothesized that the organism is continuously sampling, processing, and evaluating information in a probabilistic way:

One of the comparatively neglected tasks of a molar environmental psychology is to find out the extent to which environmental hierarchies of probabilities of object-cue as well as of means-relationships do find a counterpart in similar hierarchies of evaluation by the organism. This would mean that the environmental probabilities be first ascertained for all of the cues or means involved, with, say, the normal life conditions of the organism taken as the defining reference class (Brunswik 1943, p. 259).

The idea of a human being adequately performing as a (skilled) intuitive statistician was doubted because of the seemingly poor performance of doctors in regard to medical diagnoses (Meehl 1954) and, later, because of the research regarding the paradigm of heuristics and biases in human judgments under uncertainty (Tversky and Kahneman 1974). However, as also stressed by evolutionary psychology, probabilistic information processing in the sense of Brunswik does not require mastery of probability calculus. Rather, it is based on the acquisition, and certainly in some way, on the observing and memorizing of frequencies of events (Cosmides and Tooby 1996; Gigerenzer 1997; Gigerenzer and Kurz 2001; Gigerenzer and Murray 1987). From this perspective, the environment is, instead, the provider of statistical frequencies (Hursch
Fig. 2 The Brunswikian Lens Model in its original shape (Brunswik 1952, p. 5)

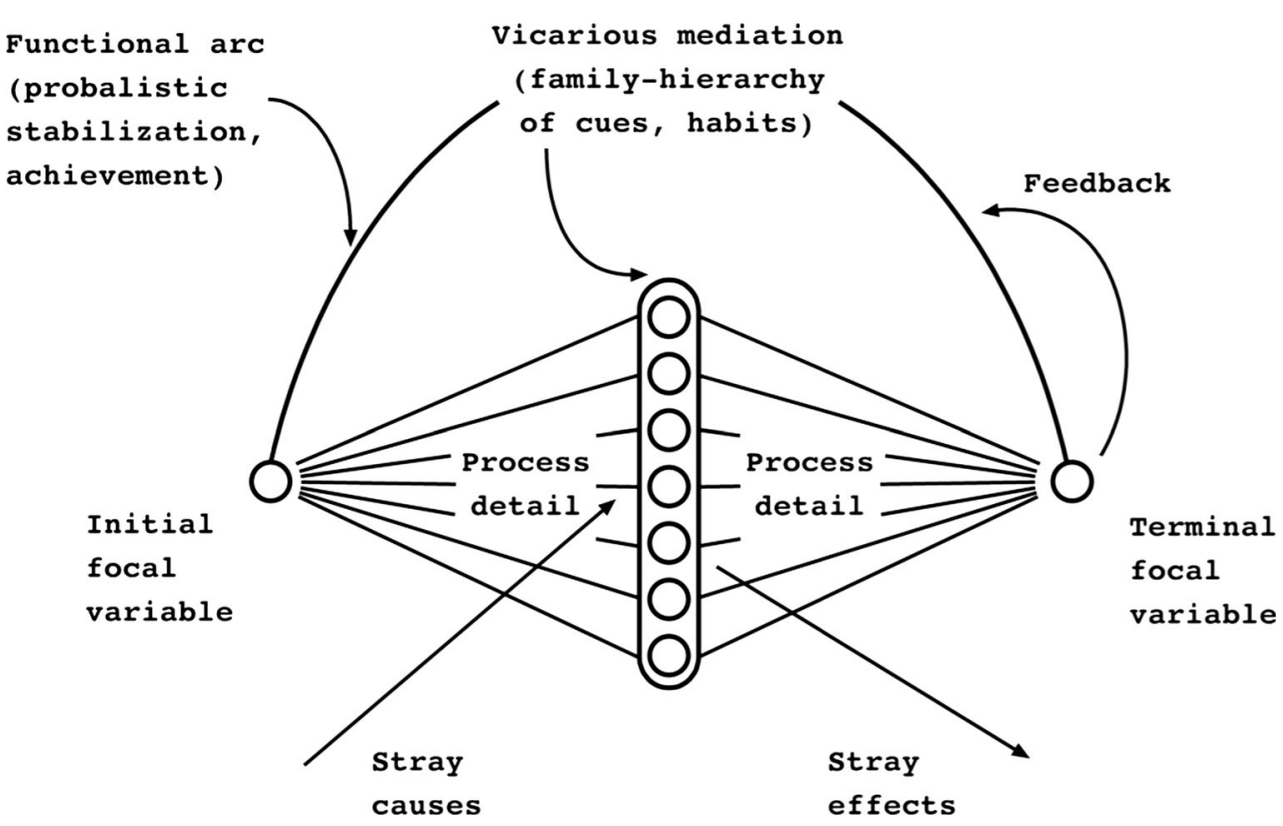


et al. 1964) that constitute more or less biased recorded experience rather than (real) probabilities.

The basic message is that, in any case, a human system approaches the environment incompletely, i.e., with uncertainty (for which probability is a scientifically respectable conceptualization). There is an upper ceiling for reducing environmental uncertainty. From an epistemological perspective, the butterfly effect (Hilborn 2004), in which an extremely small event (e.g., the flight of an insect) may cause a global catastrophe, as well as Heisenberg's indeterminacy principle (Busch et al. 2007), which reveals that the observation of properties of an atom (such as position and momentum) can affect these properties, may serve as explanations.

\subsection{Vicarious mediation (P4)}

Vicarious mediation applies if there is a high level of ambiguity between the distal and proximal cues or if certain cues are missing. According to Brunswik, an organism is prepared-presumably due partly to nature and partly to nurture - to replace, buffer, embed, or mediate certain missing or unreliable cues, using other cues that include more information about the missing one.

The environment of an organism has the character of a complex causal texture (Kausalgefüge) in which certain objects may function as the local representative (die Stellvertreter) of other objects; these latter to be called as the entities represented (die Vertretenen)

(Tolman and Brunswik 1935, p. 73).

Vicarious mediation may be seen as a buffering process that increases the robustness and resilience of the perceptual system; it produces stable, sufficiently accurate, and functional relationships when facing "relative chaos" (Brunswik 1952, p. 20). Micromediation is primarily related to the left side of the lens and the probabilist relationship between distal and proximal cues in an overly complex environment, which shapes what is called ecological validity (see below). By contrast, macromediation is more related to central processing in the organism for reaching a successful achievement and refers to the right side of the Lens Model. The latter has also been called policy capturing (Dhami et al. 2004) and focuses on the way human judgments are made.

Brunswik's goal was to "establish a multidimensional psychophysics which includes the distal environment within its scope" (Brunswik 1957, p. 78). Here, the idea of ecological validity emerged. Environmental cues "should be utilized in accordance with their validity" (Brunswik 1956, p. 141). Ecological validity refers to the validity of a cue, for instance, of a perceptual variable, in assessing the state of the environment. The idea of "environmental hierarchies" and the acknowledgment that there is a kind of irreducible uncertainty in the environment plays a role. But_in a natural environment_an organism learns that some "object-cue as well as some means-end relationships" (Brunswik 1940, p. 259) are more reliable than others. Thus, the "evaluation of the environment" by an organism in regard to perception (but also in respect to what (re)action should be shown) has to acknowledge the hierarchy of more or less reliable and useful cues.

The regression model (mostly of the linear type, but there are also nonlinear applications; see Hamm and Yang 2017) provides a straightforward, mainstream model that allows the representation of both the probabilistic relationship of distal events to proximal cues in perceptions (i.e., vicarious mediation) and of the probabilistic relationship of proximal cues to the achievement or "terminal focal variable" (see Fig. 2). However, in this author's opinion, linear regression was rather a helpful "means of representation" (Brunswik 1940, p. 69) that allowed Brunswik to comprehensively communicate the multidimensional character of information processing, rather than a ubiquitously valid quantitative model (see below). Brunswik's understanding of perception, judgment, etc. went beyond the weighing and summing principle and the conception of "the perceptual system as an intuitive statistician"" (Gigerenzer and Murray 1987, p. 74) that juggles Bayesian calculus and beyond the linear regression model as a descriptive tool.

Brunswik was aware of the multiplicity of modes of thought and distinct intuitive and analytic (inner peripheral and central) processes (Scholz 1987). "In humans, the two levels of cognition coexist, mostly in peace, sometimes in conflict" (Brunswik 1956, p. 91). Brunswik called the two processes perception and thinking, and he argued that "perception lingers in the twilight zone of compromise" (p. 91). Whereas errors in the mode of perception and intuition follow normal distribution characteristics, the distribution of errors in thinking or explicit reasoning follows different characteristics. This naturally implies that vicarious mediation (i.e., the processes on the right side of Fig. 2) calls for explanations other than those offered by linear model-related correlations and refers instead to what has been called causal texture.

\subsection{Representative design (P5)}

In the standard ANOVA design of experimental psychological research, "the natural covariation among variables is eliminated" (Dhami et al. 2004, p. 978). Thus, subjects may be exposed to causal textures that may even be impossible in the real world. Brunswik considered experiments with factorial designs appropriate only for obtaining answers to pivotal questions, the answers to which should 
identify which branch of the theory-building research should proceed. He was skeptical with respect to the analysis of variance (ANOVA) design type, in which experimenters systematically manipulate certain independent variables when following the principle of ceteris paribus, i.e., the "rule of one variable" (Hammond 2006) manipulation, whereas all other situational characteristics are kept the same (Girod et al. 2011). This would often result in unrealistic situations.

Brunswik argues that we can only understand organismic behaviors if we investigate them in their natural, ecological environment. Otherwise, "the generalizability of findings will be limited," and researchers will be "confined to a self-created ivory tower ecology" (Brunswik 1956, p. 110). Although the systematic (ANOVA) design is considered the only method of empirically testing cause-impact relationships, variables are connected (and dependent) and may not be arbitrarily disentangled (and manipulated as independent variables). Rather, experimental research should approach normal conditions of life or experiences. Otherwise, it demonstrates no situational or ecological generalizability (Hammond 1954). Thus, Brunswik suggested replacing classical experimental logic with a focus on proving strict laws using a more correlation-based procedure.

Brunswik was stressing that subjects' behaviors should be investigated with reference to the whole population of stimuli. In representative design studies, the disentangling of variables was done after (by multivariate statistical analysis) and not before the experiment by constructing an experimental design. The concept of representative design was refuted by all of the leading scientists of his time. In particular, the (factor-analysis related) statistical, correlation-based "after-analysis" was seen "as an instrument of the devil" (Hilgard 1955, p. 228) and a threat to the nomothetic approach. In discussions about empirical methods, Brunswik's took a humbler view and recommended a " "clinical" approach as contrasted with the nomothetic, more general law-finding ..." one (Brunswik 1946, p. 119). Social judgment theory may be seen as an example, as it targets the improvement of some kind of clinical decision making.

We want to note that representative design is related to ecological rationality, i.e., the organism's ability to use cognitive processes is adjusted to the environmental constraints. This is also the core of the effectiveness of heuristics. You may evolutionarily stably (see P6) utilize simplified cognitive heuristics to exploit structures of nonrandom order in an economic manner. This approach may fail (we might speak about a cognitive ecological fallacy) if the (correlations of the) environmental cues change and the rules of judgments have to adapt.

\subsection{Evolutionary stabilization (P6)}

This principle includes the learning of the human system. As can be understood from the terminology "functional arc (probabilistic stabilization, achievement)" (Brunswik 1952, see Fig. 2), it includes an evolutionary mechanism of adaptation and probabilistic achievement. Brunswik states:

A semicircular arrow [in Fig. 2] is appended in the figure to the terminal focus to indicate that lens patterns do not stand in isolation but are apt to reflect back upon the organism in a future state in what is now sometimes called a "feedback" loop... (Brunswik 1952, p. 20)

Evolutionary stabilization can be (under certain ideal constraints) operationalized by means of signal detection theory (Green and Swets 1966). The idea is that we have different types of errors, such as a false alarm or a miss (i.e., we fail to detect a signal of interest) and correct responses (i.e., correct identifications or rejections). In a specific situation of perception, judgment, and decision making, each of these four types of outcomes has certain costs or benefits. Thus, the accuracy of the judgment or behavior has to be adapted to the long-term costs inherent in different types of errors or correct responses. It is most interesting that Brunswik acknowledged this basic rule of evolutionary adaptation.

\subsection{The Lens Model figure}

As mentioned, Brunswik viewed the Lens Model as a meaningful tool for demonstrating the principles of TPF. Figure 2 displays the initial focal variable and a terminal focal variable. The initial focal variable may be a specific object whose size must be assessed, a patient's disease that should be diagnosed, an urban system's current state that may become of interest for transitioning, or something else that is the focus of an organism. There are lines between the focal variables and the circle icons in the middle. These icons are meant to represent subsystems of the organism's psychophysical system (Brunswik 1952). Brunswik did not use a specific term for these icons. Some researchers call them perceptors (Scholz and Tietje 2002), others, percepts (Goldstein 2006). We find a similar Lens Model in the (probabilistic) perceptron theory "for perceptual recognition, generalization, recall, and thinking" (Rosenblatt 1958, p. 386). The perceptron approach developed in the early stages of cognitive psychology, artificial intelligence, and artificial intelligence. The approach took a sophisticated, quantitative, mathematical learning theory approach when referring to complex models of neurons and neural networks and simulation experiments of that time (Rosenblatt 1961). 
For Brunswik, perceptors represented the proximal cues that were taken from the distal stimuli of an issue of interest (i.e., the initial focal variable). The relationship between the subject and the information sampled by the perceptors is of a probabilistic nature, such as the organismic information processing of the proximal cues when constructing an initial focal variable. This is expressed by the phrase stray causes. The most essential property of the presented process is vicarious mediation, i.e., the use of proxy cues that may substitute for or supplement certain cues. The phrase family-hierarchy of cues is chosen, as the organism has learned that some cues are more suitable to serve as proxies for others (out of a set or family). In light of current discussions, the use of the term "habit" is of interest. Here, Brunswik referred to Hull (1934), who argued that organisms take that route of behavior and information processing that requires the least amount of effort. Taking a Darwinian perspective, the cognitive achievement attained by a terminal focal variable (an estimate, judgment, decision, or behavior) receives feedback via the functional arc. Brunswik was talking about probabilistic stabilization as, also, accurate perception or proper decisions that may be penalized in cases where a wrong decision may result in a better performance. The use of safety belts in cars may be taken as an example; while they are beneficial in most cases, under certain constraints, they have the potential to harm an accident victim.

We do not deal in detail with the multiple regression analysis-based applications of the Lens Model in social judgment theory (Gifford 1994; Hertwig and Bond 2011; Karelaia and Hogarth 2008; Kaufmann and Athanasou 2009), interpersonal conflict (Dhami and Olsson 2008), or other fields, although the regression model is included as an example in the evaluation section (Fig. 10). We assume that-depending on the mode of thought-different models of utilizing and integrating cues may be appropriate. Thus, for instance, Gigerenzer and Kurz (2001) have suggested that hierarchical cue utilization and not only weighing and summing may be appropriate in many situations.

\section{Visual perception}

\subsection{Making the sensory pattern meaningful}

Perception is a key process of human-environment interaction. In Brunswik's terms, the distal stimuli, those emerging from the initial focal variable, exist objectively and are conceptualized by electromagnetic waves. These are received by retinal ganglion cells and transferred through intermediate neural layers to photoreceptors and ganglion cells to the optic nerve and visual areas of the brain, the cell-based material-biophysical layer, which we also call the body or the hardware of human systems (Fodor 1981; Scholz 2011). Brunswik deals exclusively with the processing of cues or sign-significates, which constitute the immaterial, cognitive-epistemic, software side of perception, thinking, and decisions.

This is presumably a result of his academic background, which included graduating in engineering from the Technical University of Vienna with a follow-up masters (Staatsexamen) in mathematics and physics (Huber 2014); biological aspects did not play a significant role in Brunswik's theory. In fact, he did not mention cones and rods or physiological processes. Thus, it is interesting to consider what contributions TPF can provide to contemporary visual perception, given seven decades of neuropsychological research that often starts at the level of single photoreceptors and includes activities carried out by more than half of the brain (Moutoussis and Zeki 2002; Snowden et al. 2012).

This section elaborates whether the principles of TPF are meaningful or make sense in light of current biophysical and neurological models. We may even consider this section as part of a gentle verification (a concept defined in Sect. 5) of the TPF of visual perception. What is actually represented by the perceptors or the proximal stimuli is not completely clear and depends on the disciplinary perspective or the model we use. Neurologists might talk about slowly processed chemophysical entities. Computer scientists might talk about fast processed bit (and usually rely on the all-or-nothing activities of one a network of artificial neurons, Karayiannis and Venetsanopoulos 2013).

Some 60 years after Brunswik, we know much more about microanatomy and the functioning of the visual system. The retina has high cellular complexity and, in mammals, includes about 55 distinct cell types, among them photoreceptors, ten to eleven different cone-driven $\mathrm{ON}-\mathrm{OFF}$ signals producing bipolar cells, which form a mandatory link to the rest of the visual system, and many different types of amacrine cells, which control ganglion cell responses (for a detailed description see Masland 2001). In addition, there are three specialist receptors for certain color and black/white perception (Schiller et al. 1990). However, current theories suggest that recognition and perhaps even cognitive processing begins at the level of a single cone or rod cell. Obviously, there are highly specialized cells in the inferior visual cortex for specific and important highly complex perception such as facial recognition. This may be illustrated by the "grandmother cell" hypothesis (Gross 2002; McMahon et al. 2014). There is evidence that specific cells may reliably identify certain faces in the short term and after a long time. Here, socio-evolutionary selective pressure for the key stimulus or to use Brunswik's term, key cue face, is seen as a driver. Given the complexity of facial selectivity, the single cell 
may itself structure the complexity of information given by a face, i.e., from the mouth, nose, eyes, etc. We may postulate that, as living systems have high negative entropy (Karl 2012; Mossman 2014) both physically and in their internal information processing, sensory cells or sensory neurons participate in reducing environmental complexity (Jost 2004) by transferring information to functional cues that help to reduce internal complexity.

We want to note that this section may be seen as part of what we call gentle vefication (this term emerged in a discussion with Lawrence Susskind) of TPF, i.e., ways and methods that are moderate in causal strength (as no positivistic proving of true or false by data or logics is feasible) but which provide pieces of evidence that can be used for substantiating or refuting statements.

\subsection{How does the human visual system manage to produce a crisp image?}

In order to show how the visual system manages complexity, we exemplarily demonstrate the eye's filtering, coarsening, and coping processes using a simulation presented by visual designer Ueli Kleeb and visual researcher Heller (1997). The simulation relates to Fig. 4a, which shows a typical floral bouquet as we might see it in our natural environment. Such arrangements can be seen in certain hotels and flower shops, for example. But for some people, for example, Eskimos, the picture may not provide something meaningful (see P4). For the reader, the colors and their distribution as well as the flowers presented most probably meet the criterion of normal life conditions from an ontogenetic and phylogenetic perspective.

If you close your right eye and the flower bouquet becomes infinitely large, the proximal stimuli perceive an elliptical field with somewhat fuzzy margins, as shown in Fig. 4b. Keeping one eye closed, the nose extends into the visual field (Fig. 4c). By stereoscopic intersection, "nonsignificant" or "misleading" cues (Tolman and Brunswik 1935) are blended out. The visual field should not be mixed with the receptive field. Each cell is responsible for a small region of the visual field.

To improve the performance of the microruptured cornea (e.g., by cleaning the eye), the lacrimal gland, assisted by our eyelid movements, sprays a liquid on the cone (Fig. 4d). This supports what Brunswik called ecological validity, i.e., the accuracy by which certain cues of the floral bouquet are represented by the perceptors. An example could be the represented proximity of the centers of the yellow "eyes" of the two daisies (Bellis perennis) in the left part of Fig. 4a.

The human cornea is not perfectly ball shaped (orbicular). Thus, rays from an object fail to meet in a focal point, resulting in a blurred and biased image. This is called astigmatism (see Fig. 4e), or according to Brunswik, an example of "organismic instruments and mechanisms." These serve to smooth the equivocality (see P3) and reduce "nonsignificant and misleading" cues (Tolman and Brunswik 1935, p. 31).

The rays of the floral bouquet are projected and flipped both horizontally and vertically by the biconvex lens when reducing the size to a few square centimeters at the back of the retina, i.e., to the lower light-sensitive photoreceptors (Fig. 4f). These are the color-sensitive cones and the lightsensitive rod cells, the circuity of which is simpler than that of the cones (Fig. 5). As the lens consists exclusively of soft tissue, the stray causes (see Fig. 2) are increased. In regard to Brunswik, presumably the cones and rods, together with bipolar cells, amacrine cells, and ganglia, represent what Brunswik considered and we call perceptors. Various types of amacrine cells lie between bipolar cells and control the ganglion cells' (Masland 2001) responses. This also aligns with a factor from developmental psychology, as the retina emerges during the embryonic phase as a protuberance, i.e., a protruding portion of the brain and, thus, part of the central nervous system.

Other nose-like misleading information (see above) is presented by the capillary blood vessel network (Fig. 4g). This is perceived and blended off when integrating the proximal stimuli. The blind spot is the place where the neurons from the retina bunch together (see Fig. 3), build an optic nerve, and leave the retina (Fig. 4h). As we cannot see anything where the vessels appear, visual perception is dependent on what we call vicarious mediation (see P4). There is evidence that the filling in or surface interpolation takes place in the early visual field and not in the visual cortex (Komatsu 2006).

The density of photoreceptors decreases from the fovea to the periphery of the retina; that is why our perception is sharpest in the center (fovea, Fig. 4i). During daylight, visual acuity is highest at the point of fixation close to the fovea, a rod-free region that is packed with cones (Yuodelis and Hendrickson 1986). From an evolutionary perspective, this is important as it allows for precise hunting using spears or slingshots, whereas at night, the faster-firing, light-sensitive, but less-precise rods are at work. This division of labor suggests a (neurophysical) process of evolutionary stabilization (see P6) and differentiation.

The average human retina contains about 92 million rods and only 4.6 million cones (see Fig. 4j; Curcio et al. 1990). The density of the cones decreases faster toward the periphery than that of the rods. The cones and rods send photophenes, electrochemical signals, to the brain (see Fig. 2; right side of the process detail) to build up a proper terminal focal variable. There are different types of rods specialized on long, medium, and short waves, another 
Fig. 3 The structures of the human eye (Komatsu 2006)

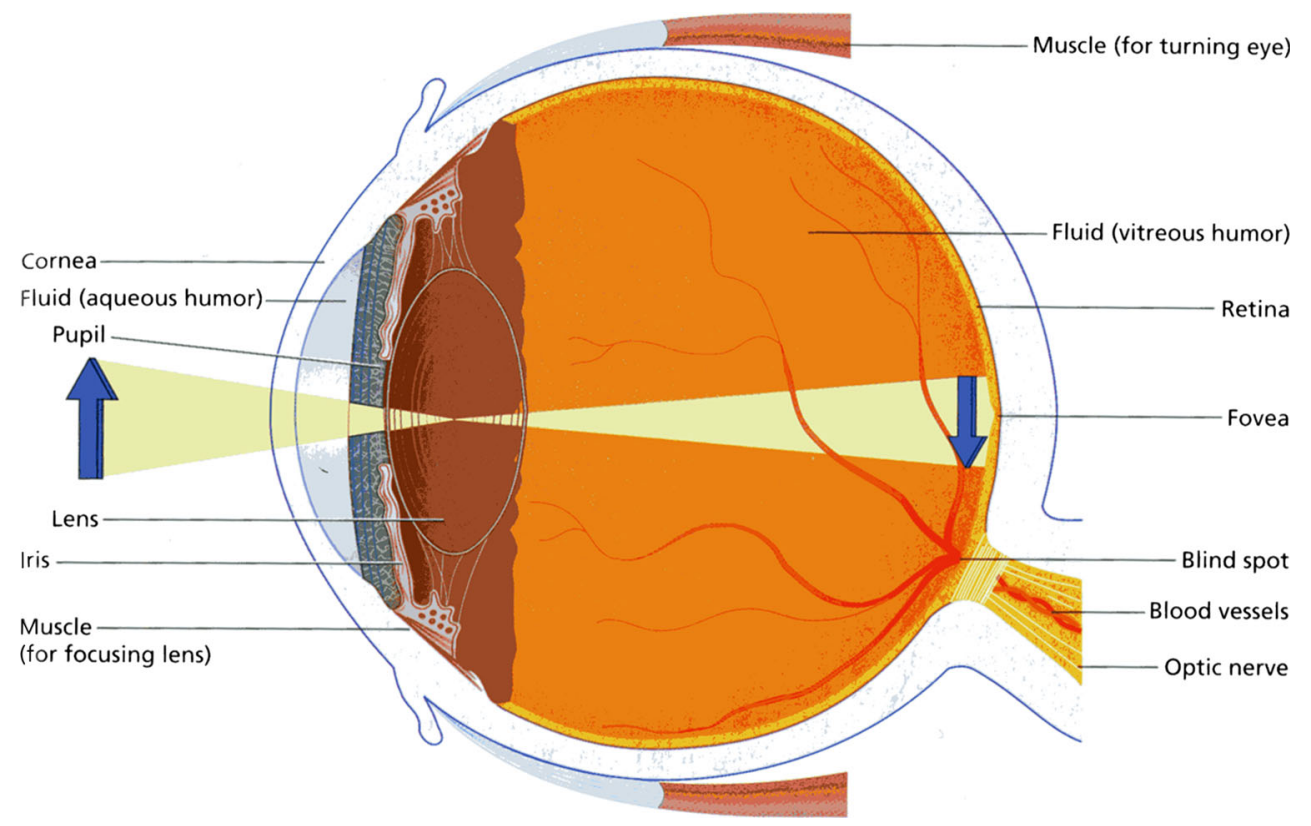

indicator for evolutionary functional differentiation (see P6).

Ganglion cells are small hubs that bundle neurally connected electrical impulses from incoming light stimuli (see Fig. 5). The functional differentiation of the differently distributed cones, which are almost missing at the fringes of the visual field, provides a reduced color impression. The blue (short-wave) and red (long-wave) processing cones are related to different ganglia. Blue cones are far more dominant at the fringes.

The post-processing of neighboring cell excitation shows mutual inhibition, with contrasts increasing (Fig. 41). This works via horizontal excitation and inhibiting of excited cones with a ring of neighboring cells (Lettvin et al. 1959). "A small stimulus excites those ganglions that lie directly under the stimulus but inhibits neighboring ganglion cells" (Masland 2001, p. 881). This comparative process reduces the redundancy of the transmitted signals. There are similar processes with rods. These findings show that the edges of a perceived object are amplified by contrast formation and that the differentiation among objects is supported.

Up to now, we have seen a series of stray causes, but no probabilistic sampling (Fig. $4 \mathrm{~m}$ ). The micronystagmus, that is, a quick vestibular or optokinetic nystagmus (also called saccades), which is independent from the movement of the body or environmental objects (Bruce and Friedman 2002), can be considered a mechanism for organizing probabilistic information acquisition (see $\mathrm{P} 3$ ). The retina, as the receiver of the proximal stimuli, is shifted about 50 times per second by a domain of 5-10 photocells (i.e., rods and cones). This is obviously accompanied by a tremendous computational process, as the location of an incoming stimulus (e.g., a light ray) can be localized by the precision of one-tenth of a diameter of a photoreceptor. This computational effort is accomplished due to a limited temporal resolution of the eye. Thus, we can see only 16-20 pictures a second in a dark environment but 50-60 pictures in a light one (allowing for the thumb cinema technology).

"We look with our eyes, but we see with the brain" (Zimbardo et al. 2005, p. 191). From the proximal stimuli in the retina, the information is transmitted relatively slowly by ON and OFF cells of the retina to the visual cortex (Gollisch and Meister 2008). The visual cortex receives the information from the rod and cone perceptor cells (see Fig. 5) with a delay of 30-100 ms where the twodimensional information is assembled by different types of synapses into a three-dimensional image. In the case of the floral bouquet, of course, the mind produces a perceived crisp image using what Brunswik called "process detail." The elements from visual sensations are combined with remembered information from the viewer's personal history, motives, and other sensations. The long-dominating idea that only the brain is compensating, reprocessing, and producing all flaws of the sensation process to construct a proper "terminal focal variable"-however-is not correct.

This can be derived from neurological research illuminating the networking of the ganglion cells. Figure 5 presents the results from an experiment where a dark moving bar was passing the visual field of larval tiger salamanders and Dutch belted rabbits (Berry II et al. 1999). Figure 5a shows the distance of the leading edge from the spike train, 

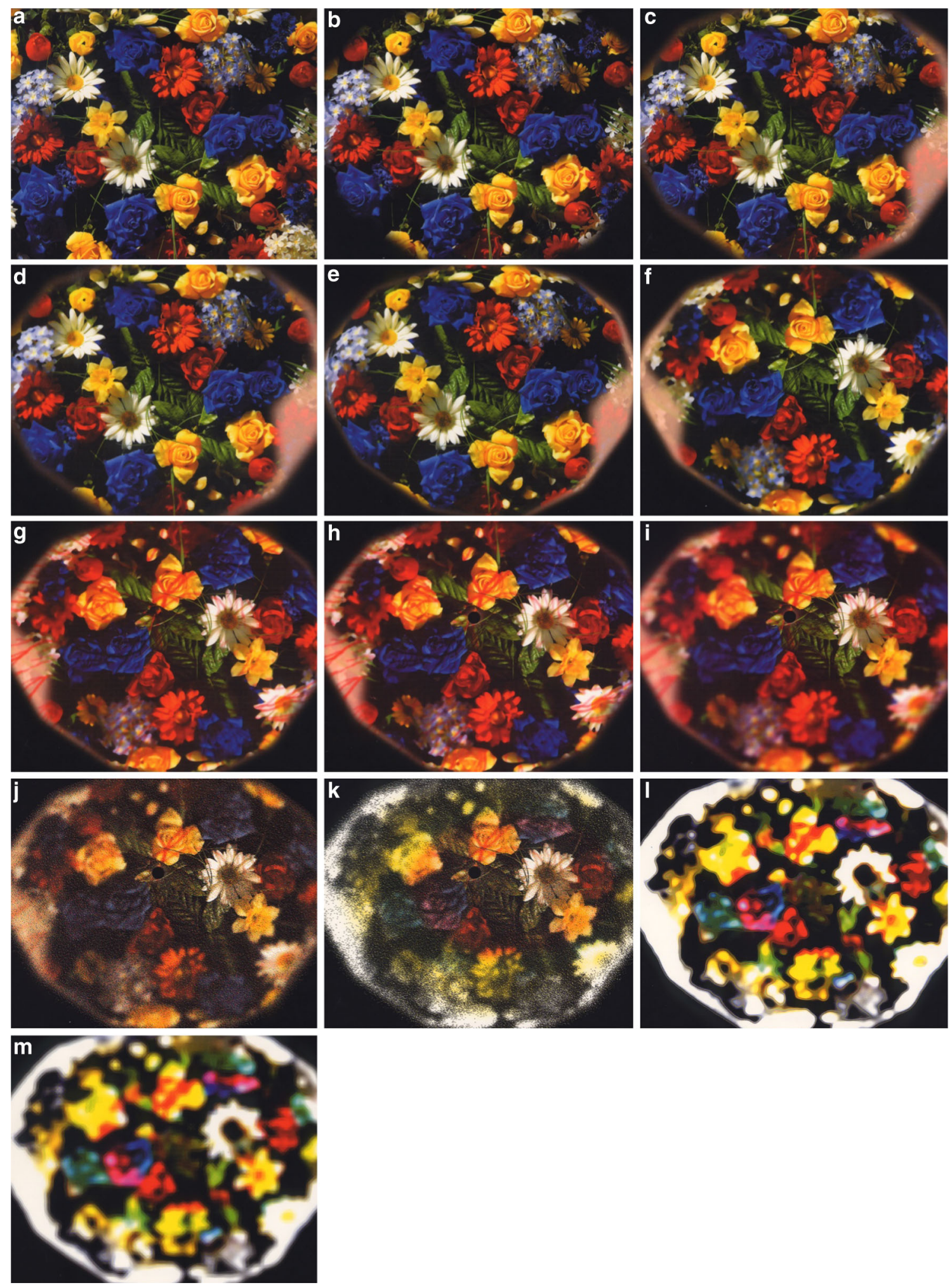

Fig. 4 The picture of a floral bouquet (a), the visual field (b), the nose in the visual field (c), the lacrimal gland liquid (d), the blurring and biasing astigmatism (e), the top-down, right-left reducing retina projection (f), the capillary blood vessel network (g), the blind spot

(h), focused crispness by the fovea centralis (i), a limited number of cones and rods (j), ganglia (k), boundary contrast amplification (l), probabilistic information sampling due to a micronystagmus (m) 


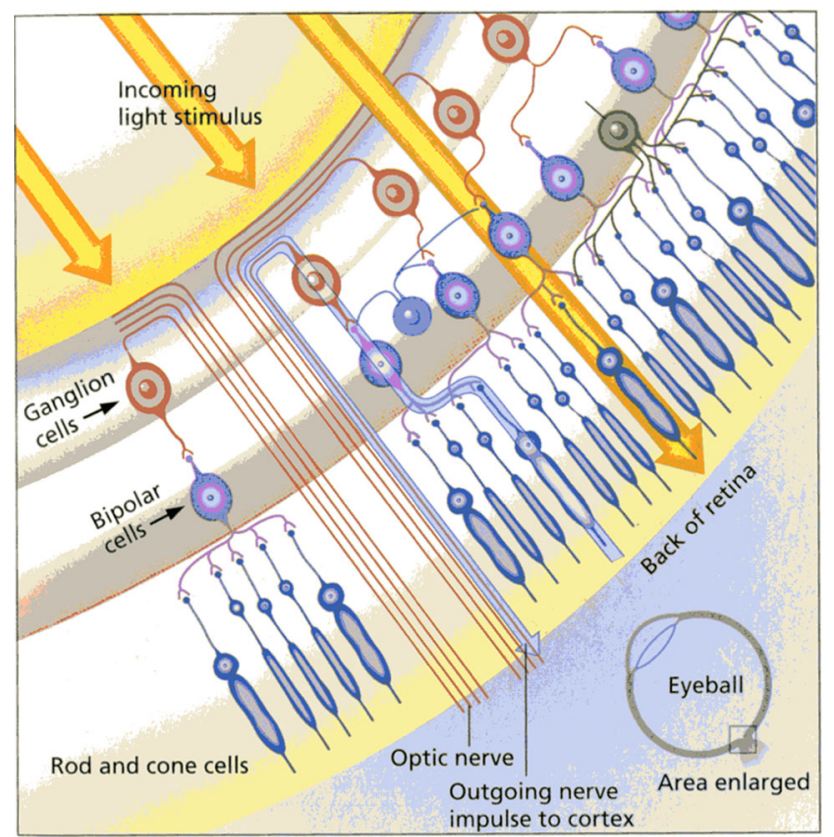

Fig. 5 The transduction of light in the retina and the three layers: rods and cone cells, bipolar cells, and ganglion cells of the retina (Zimbardo et al. 2005)

i.e., the location of the firing ganglia to the leading edge of a piece of isolated retina that was linked to a multi-electrode recorder. We can see that the ganglia are partly firing before the bar appears, and this pre-firing happens earlier if the bar moves faster (Fig. 5b). The rationale for this is that we would see a moving object too late if this networking of the perceptors in the retina did not occur. This leads us to an additional principle (Dhami et al. 2004).

\subsection{Perceptors in organisms are interlinked and operate in mutual causality (P7)}

We may learn from this that the interaction among the cells of the retina clearly goes beyond simple contrast amplification. We are facing an immediate interaction of the perceptors on a horizontal level (i.e., same cell system) for informing the visual cortex (i.e., to a superordinate organ).

We should note that P7 has already been inherent in an early paper of Hursch et al. (1964) where, in the context of the Lens Model equations, intercorrelations of the preceptors were discussed. But the presented data on the cognitive processing of the retinal cells, e.g., the identification of faces or other salient and evolutionarily essential environmental signals by "grandmother cells" (Barlow 1972; Konorski 1967), also show that receptor cells have a mind. In Minsky's terms, the single cell works as a property analyzer (Minsky 1963). As cells of the immune system do (Cohen 2000a, b; Scholz 2011), perceptor cells interact to improve the functioning of the visual system. As we have learned from neuropsychology (Roth and Dicke 2005), the perceptual system is a highly interconnected multi-level system. Distal stimuli elicit a cascade of activities in and between the different organs, and (the eyes) cells not only have a memory (see, e.g., Sperling 1963) but also support evolutionary stabilization of performance by networking (P7) (Fig. 6).

\section{The cognitive challenge of rapid sustainable transitioning}

\subsection{From visual perception via group decision making to sustainable planning}

TPF has been applied under the label of social judgment theory (SJT) (Brehmer 1976, 1988; Doherty and Kurz 1996; Hammond et al. 1975) to clinical judgments and multiple-cue learning. SJT has also been utilized to analyze conflict resolution and negotiation (Hammond and Brehmer 1973; Mumpower 2001). Others, such as Brehmer and Hagafors (1986) applied the Lens Model to investigate decisions in groups and organizations. Figure 5 presents a Lens Model by Brehmer and Hagafors (1986; see also Hollenbeck et al. 1995) used in group experiments. Three staff members $(A, B, C)$ can read or sample certain properties (cues) of a real-world issue. Let us consider the evaluation of the riskiness of a company's bank loans by a group of credit officers. The staff members have access to cues related to human resources (e.g., leadership quality), finance (e.g., business plan), and products (e.g., market pull). These cues are integrated to inform a leader (D) about whether to offer the company credit or not. This model already includes a switch from the individual to the organization, and the functional arc of validation is subject to uncertain future developments (Fig. 7).

The application of TPF to groups was done mostly in a descriptive way referring to the regression analytic variant of the Lens Model as a kind of metaphor. However, Adelman and colleagues (Adelman et al. 2003; Adelman et al. 2004) went further. They investigated in what way certain TPF principles underlie subjects' behaviors in group experiments on cue processing in aviatic control experiments.

Against this background, it is surprising that-despite the fact that "psychologists have developed countless theories about the organism" (Hammond 2001, p. 298)the questions of why and how groups can be considered as organisms has been missing in Brunswik's contributions. We address these questions and discuss how TPF can be utilized for describing and explaining ("good") group behavior. We then discuss in what way TPF principles may be inherent in planning groups' activities and how the 
Fig. 6 The anticipation of the firing of retinal OFF ganglion cells depends on the anticipation of the stimuli regarding a bar moving at varying speeds $(0.11$, $0.22,0.44,0.88$ and

$1.76 \mathrm{~mm} \mathrm{~s}^{-1}$ ); figure $\mathrm{b}$ shows the firing profiles for different rabbits (RT, RS, RE, RDP, RDN) and salamanders (SF, $\mathrm{SO}$ ) (figures taken from Berry II et al. 1999)

Fig. 7 Lens-Model-based multi-level group/organizational decision making types of OFF and ON cells for
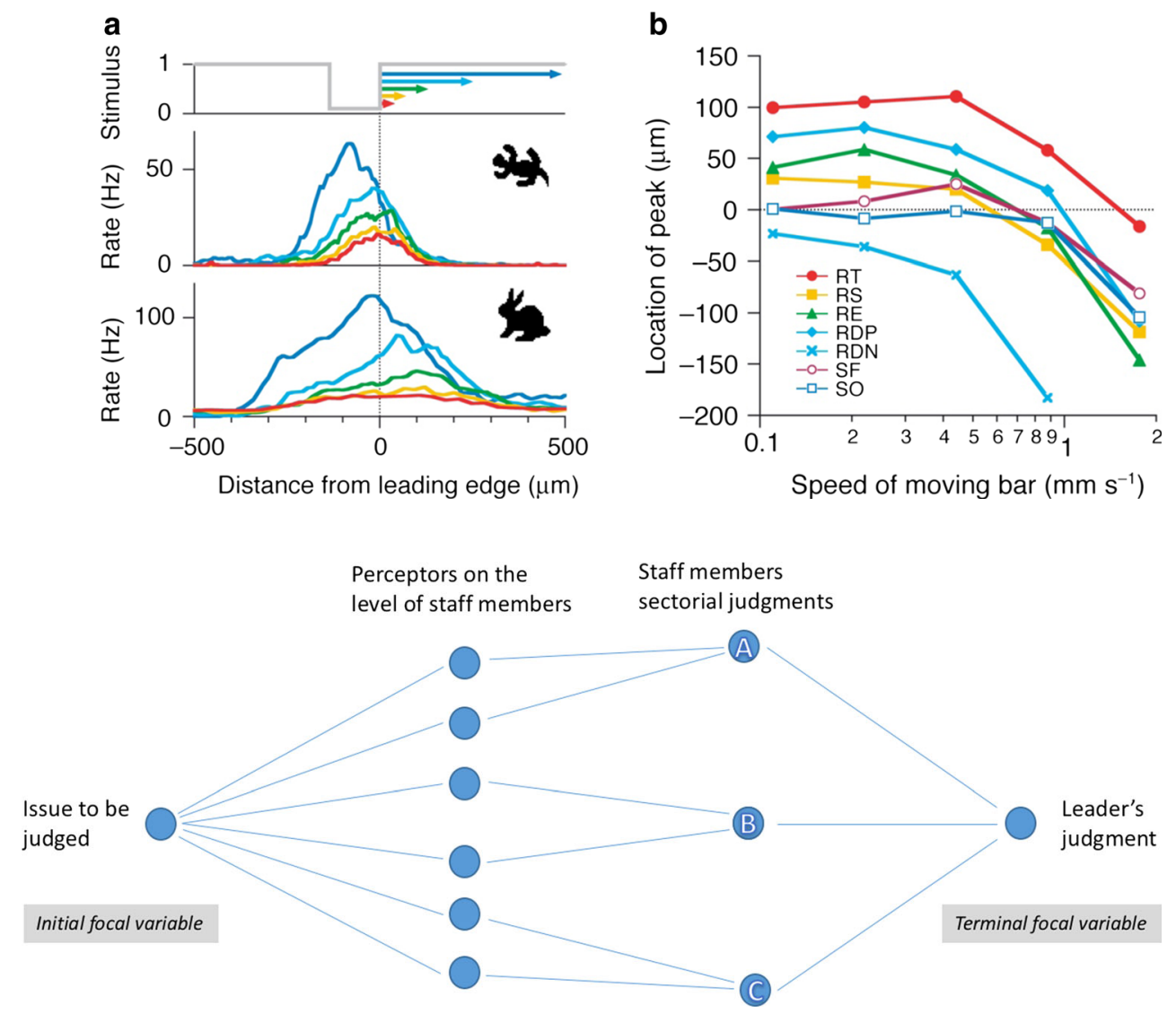

construction of sustainable planning variants refers to TPF principles. Section 4.2 reflects on how methods from decision making, such as Formative Scenario Analysis (FSA) or Multi-Attribute Utility Theory (MAUT), are meaningful aids for vicarious mediation in cue acquisition for representing, projecting, and integrating environmental systems.

\subsubsection{How are groups organisms?}

An organism is commonly defined as an entity or unit that is "more fundamental than its elements and... whose relations [among parts and members] and powers or properties are determined by their functions in the whole" (Merriam Webster 2017). A human individual, the eye, and a photoreceptor cell are genuine biological organisms of different scales, the vital processes of which cannot be defined without looking at the whole. Science helps to identify and describe the parts (e.g., the organs of an individual), their functioning, relationships, and properties. But in addition, systems above the level of the individual, such as the group or organization, can be conceived as organisms. Biologists call these superorganisms (D. S. Wilson and Sober 1989). The cell-based definition of all human systems ranging from cell to human species (which includes a body-mind complementarity; see Sect. 2.2, last paragraph) shows how organisms of different scales can be consistently related.

A critical question is: How are the visual system and a group alike (or very similar) and how are they different? A main difference between (biological) human systems below the level of the individual and (social) systems above the level of the individual is that the former follows the principle of homeostasis, whereas the latter follows the principle of homeorhesis (Scholz 2011). Homeostasis includes a set-point control regulation (e.g., of body temperature), whereas such regulation is missing in a superorganism. Homeorhesis means that system dynamics return to trajectories that can be conceived as rules and mechanisms of regulations but not to steady states (Scholz 2011). The refutation of the Gaia hypothesis (Lovelock 1995) has demonstrated the latter.

According to the cell-based definition, all human systems have a material-biophysical layer (a body) and a cognitive-epistemic-sociocultural layer (also called mind). The mind of the perceptual system provides an interpretation of the environment when using cues derived from light patterns that are in an individual's visual spectrum. This has been the subject of the previous section. In this section, we discuss whether and how TPF principles this is related to biophysical patterns. underlie the mind of the group. In Sect. 3, we sketched how 
The mind of the group can be defined as the rules and entities of the regulatory system that govern group behavior and performance. The mind includes group norms, values, preferences, decision rules (that are culturally shaped, Brewer and Venaik 2014), criteria (cues), and properties that are conceived as in-group or out-group behavior, group identity, rules of communication and for penalizing (deviant group behavior), group intentions, group knowledge, and group culture. Group behavior is shaped by bottom-up and top-down processes between the minds of the individuals and of the group. This is a cognitive-epistemic-sociocultural view of the group as an organism (Scholz 2011, p. 419). In biology, the concept of a group as an organism was abandoned for some time after a DNA-centered view dominated the understanding of life and evolution. But as key processes of evolution cannot be explained without considering the superorganism, the concept of groups (colonies, etc.) as organisms was revived (Hölldobler and Wilson 2009; Wilson and Sober 1989, 1994, 1996, 1998; Wilson and Wilson 2007; Wilson and Nowak 2014).

In the following, we define a sustainability planning group as a temporary or permanent designated group of members whose task is to assess critical aspects, develop strategies to overcome barriers, and design future visions, states, and processes for sustaining an (coupled humanenvironment) system. Typical systems can be urban or regional communities, social support and health systems, environmental systems (e.g., cities, oceans, biogeochemical cycles), critical industries, or digital environments. In recent years, guides for such teams have been developed (Batan et al. 2011; Foley 2014).

\subsubsection{Future sustainable transitioning of systems as a terminal focal variable}

Sustainable transitioning has the characteristics of an illdefined problem. There is uncertainty about the initial state, about the target state, and about the barriers to overcome. From a system perspective, sustainable development is conceived as (1) ongoing inquiry on (2) system limit management (i.e., "avoiding hard landings or creating resilient systems"; Laws et al. 2004), (3) in the frame of intra- and intergenerational justice. If we consider sustainable transitions, however, we look at not only a proper representation of the status quo of an (environmental) system but also at its prospective state. The challenge to design (which is a cognitive task) future sustainable systems and to transform current states of systems to sustainable structures is focused in the following. Given the ill-defined nature of sustainable transitioning, the validation of products of sustainable planning (i.e., of the terminal focal variable) is a special issue and touches critical issues of what decision researchers call calibration (Baron 2004) or correspondence (Dunwoody 2009; Hammond 2000) of models. If we look at communities or cities, there are three main approaches, i.e., (1) benchmarking by examples of best practices, (2) evaluation by sustainability indicators (Bell and Morse 2008, 2013; UN 2016) best on systemic aspects such as biodiversity, reference to resilience indicators of social systems (Scholz 2017a), and (3) (sustainability) expert judgments (de França Doria et al. 2009; McBride et al. 2012; McDaniels et al. 2010). These methods are of limited reliability and validity, particularly if we consider the multidimensionality of systems and the imponderabilities of social systems. However, in principle, this uncertainty hampers but does not make gentle verification (see above) impossible.

\subsubsection{How does TPF relate to sustainable planning practices?}

Between 1994 and 2002, the author of this paper co-led 21 large-scale case studies (of approximately one-year durations), predominantly on urban, regional, and industrial transitions or the transforming of policy processes (Scholz et al. 2007; Schori et al. 2009) and participated also mostly in operative planning groups (Scholz and Steiner 2015b). Several studies were also conducted on global resources management (for publication information, see no. 1-6, 7-13, and 17-23 in the supplementary information of Scholz and Steiner 2015b). The idea of utilizing TPF as a reference framework for sustainable planning developed during the ETH Department of Environmental Systems Science case studies on sustainable transitioning of a 50-ha industrial brownfield to a residential area (Scholz et al. 1996; Scholz and Tietje 1996; Scholz et al. 1997). Brunswik's Lens Model for TPF was used (as a metaphorical template) to present eleven methods from decision and operational research for (real-world) case representation and the formation of planning variants and the evaluation of these, as well as for methods of case transformation (see Scholz and Tietje 2002). All (science) members of the planning groups received training on the methods including the principles of TPF (for the latter see p. 29-43 Scholz and Tietje 2002). Examples of these methods are Formative Scenario Analysis (FSA), Multi-Attribute Utility Theory (MAUT) assessments, System Dynamics models (SD), Material Flux Analysis (MFA), Life-Cycle Analysis (LCA), and Biological Potential Analysis (BEPA). Most of these methods are used frequently by think tanks, sustainable planning groups (Street 1997), transdisciplinary project teams, and international panels such as the IPCC.

There have been 97 planning teams in these 21 largescale studies including approximately 1300 master students and faculty members working in 97 (i.e., 21 steering and 76 
operating) planning groups in the above-mentioned largescale studies. Further, more than 2000 practitioners participated (for detailed data see Scholz and Stauffacher 2010; Stauffacher and Scholz 2013). Some studies were genuinely transdisciplinary, and practitioners and scientists took co-leadership roles (see, e.g., Scholz et al. 2014). Practitioners comprised about half of the team members in all steering groups and were involved in some of the operative planning teams.

As the above studies focused on sustainable transitioning of cases and not on how planning groups function, unfortunately no detailed data are available that provide indepth information about the presence, functioning, and impacts of the proposed principles of TPF. The following description is thus based on the author's (subjective) experience and expertise. Section 4 concludes with Table 1, which shows how the principles of TPF can be utilized to describe and understand visual perception and the ideal functioning of planning groups.

\subsection{Planning groups' sustainable transitions described by the Theory of Probabilistic Functionalism}

\subsubsection{Relating planning groups' activities to TPF principles}

Box 1 describes five typical planning steps in a typical project on sustainable transitioning. Step 1 refers to the (problem) definition of what the subject of a sustainable transition is and what conception, assessment, or transition is wanted. In planning, the terminal focal variable can be operationalized by a guiding question, such as "What should the urban traffic system look like in 30 years in order to meet key criteria of sustainability?" Sometimes the problem emerges from a case (e.g., a specific city); sometimes we identify a problem and then look for a corresponding case. The definition of the system boundaries, i.e., of what is included in the case, corresponds to the initial focal variable. As studies in sustainable transitioning are purposeful or functionalist (see P1), they are related to the goal or terminal focal variable (for the following, see Fig. 2). The functional arc relates to the question of whether or not the outcome of planning (Box 1, Step 5), i.e., the conception of a future state of a case/ system (see Fig. 8), will strengthen the viability of the case. We note that in the following by means of simplicity we focus the construction of planning variants and exclude group dynamics, external constraints such as lobbying.

Step 2 refers to qualitative and quantitative case representation. Real-world cases are from the natural environment. But the representativeness idea is essential in case selection in a similar but logically inverse way, as in the random sampling of subjects in experiments. A sample represents (we hope) a well-defined population. A case has to be representative for a tangible subset of the (natural) environment. This is expressed in: "A case is considered from a specific perspective and with a special interest. It is unique, one among others..., and always related to something general" (Scholz and Tietje 2002, p. 1).

In an FSA-based scenario construction (Scholz and Tietje 2002; Tourki et al. 2013), we generate a semiquantitative set of levels of impact factors (see second left-hand column in Fig. 8). These are also called cues, descriptors $\left(d_{k}\right)$, or perceptors. In SD or MFA, the stocks are the perceptors. In FSA, links between the variables are judgments about how one strong impact factor affects another one. The impact strength may be binary ( 0 means no impact; 1 means a strong impact), or the strength may be rated according to an ordinal scale (none, low, medium, high), depending on the knowledge of the system and on the relationship of the system variables. The term "formative" in FSA indicates the functionalist perspective (see P1), as the process of analyzing and describing possible future sustainable states of a case is done "to give form" to a case. This is particularly true if practitioners are actively involved in the construction of the scenarios, as what has been planned or designed can become a maxim of preference and action.

In terms of the TPF, the links between the distal and proximal variables decompose or facet the system and system properties (see also Fig. 8). What cues are considered, defined, and maintained (after reducing the set) may be considered subject to probabilist stray causes (P3). Depending on the members of the planning team involved in this phase, the issues that have been discussed by some of the project team members in other projects, or what factors have been stressed in the latest news (recency effect), a different set of variables may result. Thus, the principle of vicarious mediation (see P4) is most important, as the set of-in some respects, probabilistically constructed (see P3) - impact variables must be sufficient for representing the case in a valid way in order to serve the purpose of sustainable transitioning.

An appropriate definition of the case variables by the case study team calls for certain epistemic capabilities. From the side of the scientists, there has to be adequate case understanding for approaching representativeness. If we distinguish levels of epistemics from erfahren (experiencing) to verstehen (understanding), begreifen (conceptualizing), and erklären (explaining), the challenges on the side of the scientists (who usually do not live in the geographic case region, for example), the challenge for scientists/planners is to understand the case by acquiring (case) experience. In terms of Brunswik, this means that the case has to become part of the "historic axis" (see 2.2) 
Table 1 Principles of the TPF (see Sect. 1) for visual perception and planning teams' sustainable transitioning

\begin{tabular}{|c|c|c|}
\hline No. & Label & Visual perception \\
\hline P1 & Functionalism & $\begin{array}{l}\text { The eye is an economic (purposeful) } \\
\text { means for spatial perception to } \\
\text { secure survival (sufficiency } \\
\text { principle; perception must be good } \\
\text { enough). Environmental cues and } \\
\text { terminal focal variables were } \\
\text { evolutionarily formed }\end{array}$ \\
\hline $\mathrm{P} 2$ & $\begin{array}{l}\text { Dualist } \\
\text { human- } \\
\text { environment } \\
\text { system }\end{array}$ & $\begin{array}{l}\text { The visual system has an inner body } \\
\text { (representation) and an outer human } \\
\text { body environment. The genesis and } \\
\text { processing of distal (environmental) } \\
\text { and proximal (internal) stimuli are } \\
\text { subject to different systems with } \\
\text { different rationales }\end{array}$ \\
\hline
\end{tabular}

P3 Probabilistic information acquisition and processing

\section{P4 Vicarious} mediation

P5 Representative design

P6 Evolutionary stabilization perceptors
(A limited number of) Stimuli are probabilistically acquired; also, the processing is subject to stochastic impacts (stray causes)

(Due to imperfect and probabilistic cue sampling) The visual system has to rely on substitution of those cues that are important but not sufficiently accessible

The perceptual system provides bad performance if has to cope with the texture and structure of which does not meet the experience of the perceiver (and which asks for adaptation); ANOVA designs that vary (ceteris paribus) single variables tend to induce findings that may not be well generalizable to common ("natural") environments

The generated visual image, estimate, or judgment has to be good enough for the perceiver to survive in the discourse of evolution

The perceptors and thus the utilization of information are interlinked. The linkage of the perceptors (of an organ) may help to compensate, e.g.,

Planning teams' ideal sustainable planning

Given a proper problem definition, planning teams are economic means for the sustainable transitioning of a case/system of interest by designing future scenarios that show higher resilience than the status quo

Brunswik argued that understanding the environment is the most essential issue. This includes the understanding of the hierarchy of human systems (e.g., individual, group [e.g., planning groups], organization, society, human species, their different rationales, and their interactions as well as the material, biophysical environment for establishing resilient coupled human-environment [P1])

All steps of a transdisciplinary transition project are highly dependent on probabilistic impacts (e.g., on who may participate in what meeting) due to the myriad of impacts included

A planning study should consider in depth what spectrum of stakeholders, range of system, data, etc. are needed to develop an evolutionarily stable (and perhaps socially or sociotechnologically robust) system; the substitutability of likely missing variable, stakeholders, data, etc. should be planned

Planning is often related to cases or exemplarily selected model systems. Representativeness is cultural (such as ecological rationality). The selection of the system should reflect whether what might be learned can be transferred to other cases/systems

Planning studies should contribute to making systems more compatible, viable, and resilient in the discourse of sustainability and the competition of systems. (Partial mid- and longterm) Validation by benchmarking, indices, sustainability and expert judgment judgments necessary

System variables and system actors are highly interdependent. The study of interlinkages of impact variables is a prerequisite of avoiding
Causes of planning teams' insufficient sustainable planning

The wrong problem, goals, and/or system boundaries defined or set (partly due to not having sufficiently experienced how the natural system functions)

Planning groups often forget the holistic view, focus on (technical) subsystems (of infrastructure), do not acknowledge multidimensionality and hierarchical system rationales (of governmental planners) and the coupled humanenvironment system that is planned

The limited reliability of (survey, interview, inventories, etc.) data is underestimated. Triangulation of methods and interpretation (intuitive and analytic) are needed

A planning study team does not sufficiently deal with substitutability of important aspects, variables, stakeholder groups, etc.

Planning variants do not acknowledge the ecological rationality of the users. The cultural dimension of representativeness is ignored in (developmental) and other planning projects (using solar cookers and energy has the status of social inferiority)

No validation strategies are planned (only the planning). What is planned is believed to be good

The interaction of variables and particular unintended side effects of planning means are not sufficiently considered 
Box 1 Five steps of sustainable transitioning

The different methods may be ordered along five steps of a problem-solving cycle that proceeds from (1) problem definition via (2) problem representation, (3) the construction of options for future development, and (4) the evaluation of these options to the (5) transformation of these systems. In more technical language related to the TPF, we may define the following steps

When investigating sustainable transitions, the task consists of the following

Step 1 (Problem definition and goal formation) The planning team defines system boundaries and the layer of the system, i.e., the initial focal variable, which should become the subject of a sustainable transition. The terminal focal variable is the future state or new conception of the case (see Fig. 7)

Step 2 (Case selection and system representation/scenario construction) The challenge is to represent the case by a set of variables. We may formulate that we look for a set of cues, which may be subsystems, aspects, system variables, or impact factors that sufficiently represent the case and its dynamics under the perspective of sustainable development. In the following, we will call these cues descriptors, as they serve to describe the case

Step 3 (Projecting, constructing of scenarios/alternatives) In the case of sustainable transitioning, the challenge is to identify one or more future settings that may be considered sustainable. For this, the construction of a set of possible future states-we call these scenarios, $S_{J}$-is needed

Step 4 (Scenario evaluation) The planning team is challenged to identify one or a small set of scenarios that are considered sustainable. This calls for a scenario evaluation. If we refer to a multi-criteria assessment, we are looking for a set of attributes or sustainability criteria, $u_{k}$, that may be used for scenario evaluation and subsequent selection (e.g., when identifying that one (or those) that is (are) considered sustainable)

Step 5: (Socially robust orientations or planning variants) The last step consists of developing strategies or (socially/sociotechnologically robust orientations for the key actors of a system that support a sustainable transition of the case. These orientations are based on negotiation processes (including the tradeoffs of values and interests) among the stakeholders and serve as references in the process of transformation

In terms of the TPF, the five steps are (1) identifying a terminal focal variable that is of functional (evolutionary) interest and identifying functions; (2) assessing the status quo of the case and developmental aspects by representations of different subsystems; (3) projecting and composing the different cues for (4) constructing different types of terminal variables vicarious functioning for (5) defining a terminal focal variable with high potential for evolutionary stabilization of the case, e.g., a regional system

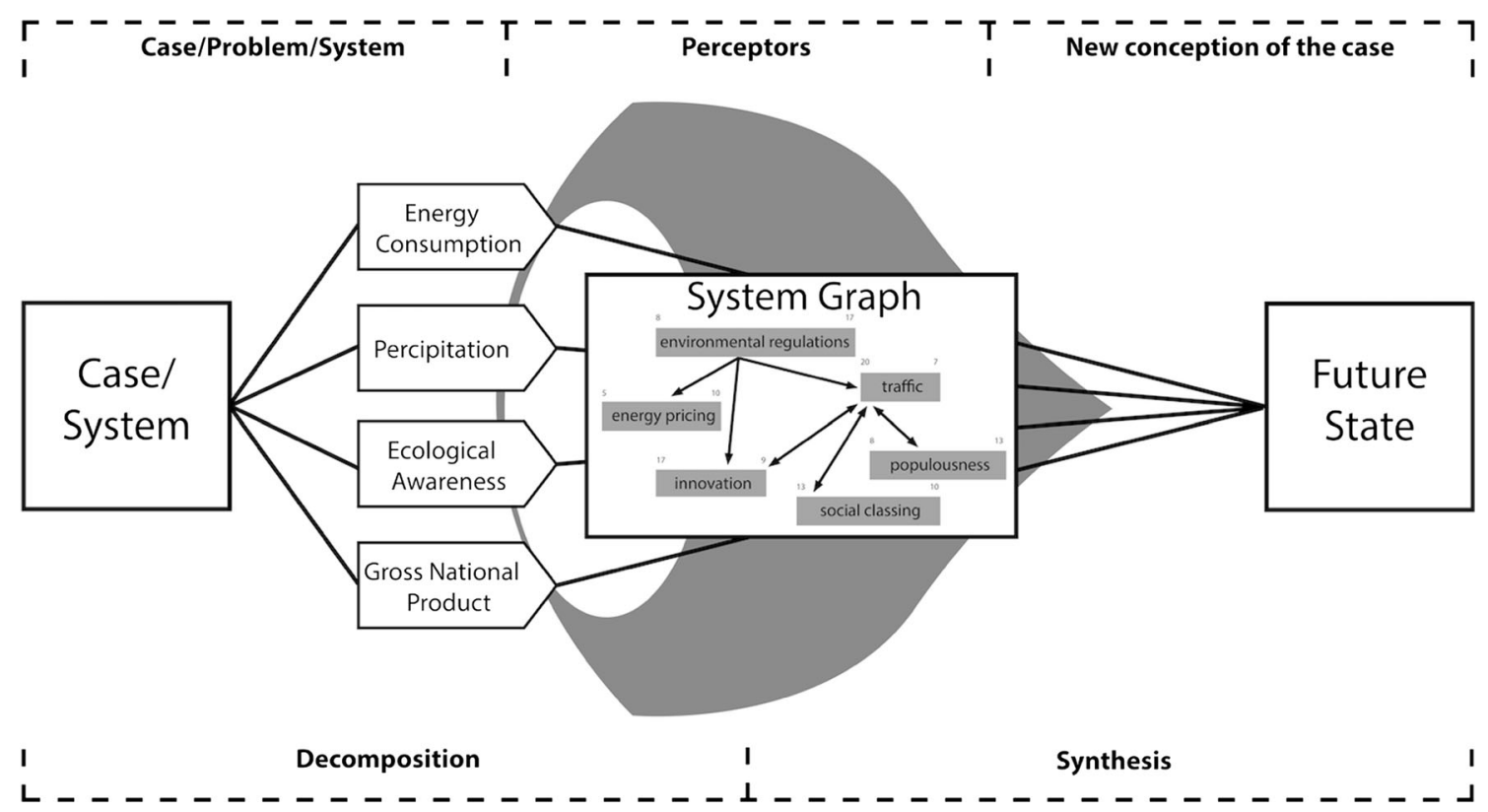

Fig. 8 The Brunswikian Lens Model for Formative Scenario Analysis (a highly simplified representation)

of the scientists, which meets the criterion of representative design (see P5). As empathy and side change are salient components, we developed a method called experiential case encounter (Scholz and Tietje 2002). Scientists have spent some amount of time in the case setting as the inhabitants do; for instance, for a rural study of vegetable farming, a scientist may take a job as a seasonal worker and harvest crops for a significant amount of time, during which some level of experiential knowledge is likely to develop. In contrast, for practitioners (who may be 
part of a transdisciplinary planning process), the challenge is to understand the scientific procedure of representing a case in an abstract form by variables. For them, the case meets the "normal life conditions" and the everyday "geographical surroundings" (see P4). This is part of what we call mutual learning; the "organism" (here, a case study team) becomes capable of integrating its knowledge in order to develop a meaningful problem definition (Step 1). The different project team members are the perceptors who gather information and insight into the case/system in a probabilistic manner.

\subsubsection{Theory of Probabilistic Functionalism and scenario construction}

We do not go into the details of FSA (for details see Scholz and Tietje 2002, pp., Chapter 9), but Fig. 8 presents several of the basic elements. Given a certain guiding question, a planning team defines impact variables (i.e., cues). A System Graph represents how strongly an impact variable affects others (the lower numbers in the middle boxes are summary scores of impact strengths) and is, in turn, affected by others (the upper numbers in the middle boxes are summary scores) and how the variables interact (see P7). The principle of vicarious mediation is essential for the most important step of FSA, i.e., the construction of the set of impact factors. In terms of Brunswik, a System Graph provides a "stabilized achievement" by "vicarious mediation" or "vicarious functioning and focusing on "ends" (Brunswik 1952, p. 16). The challenge of assembling a set of impact factors for FSA (see P5) calls for defining the factors so that they represent all the necessary information for a sustainability evaluation (which is a backward-planning view from the terminal target variable) in a way that maintains a robust "image" of the future state. This is important if several measurements/constructions are missing or biased, or if the project team has overlooked an important variable for representing the case.

In our case, "ends" includes the construction of possible future scenarios (see Step 3) that are sustainable. In FSA, a scenario is simply the combination of levels (system variable states) of impact factors. Thus, for each impact factor $\left(d_{k}\right)$, different levels $\left(d_{k}^{1}, d_{k}^{2}, \ldots, d_{k}^{k_{i}}\right)$ are constructed that may describe possible future states of the case/system. For instance, an impact variable of energy consumption ( $d_{i}:=$ energy consumption per person per year) can be judged to have two levels: $d_{1}^{1}:=$ "less than $2000 \mathrm{~W}$," equal to about $26 \mathrm{kWh}$ per person per year; $d_{1}^{2}:=$ "medium" = between 2000 and $4000 \mathrm{~W}$," and $d_{1}^{3}:=$ high $=$ above $4000 \mathrm{~W}$. Given this approach, we can formally define a specific scenario $\left(S_{l}\right)$ as a complete combination of levels of all impact factors of a case/system (formally $S_{l}=\left(d_{1}^{l_{1}}, \ldots, d_{k}^{l_{k}}, \ldots, d_{N}^{l_{N}}\right)$, if we have $N$ impact factors). Now, one (cognitive) challenge is to sort out those scenarios that are considered impossible (i.e., low-validity options) and to focus only on those that may appear in the future. According to FSA, this is done by means of consistency analysis. The (logical) consistency can be intuitively rated, but there are also formalized methods (Tietje 2005) of assigning consistency scores to concentrate on those future projections (i.e., scenarios) that seem possible based on expert knowledge.

\subsubsection{The Theory of Probabilistic Functionalism and multi-criteria assessment of planning alternatives}

The TPF, however, can also be applied to Steps 4 and 5 of Box 1, i.e., the selection of the (most) sustainable variants out of the set of sustainable scenarios and the development of socially robust orientations. The evaluation challenge is in line with the standard application of the Brunswikian Lens Model to (social) judgment theory (Karelaia and Hogarth 2008), bootstrapping (Camerer 1981; Kaufmann and Wittmann 2016), and behavioral decision modeling (Bose 2015; Glöckner and Betsch 2012; Slovic et al. 1977).

Many of the above-mentioned planning groups utilized MAUT to identify aspects of consent and dissent among different stakeholder groups for coping with tradeoffs among values (see, e.g., Scholz and Stauffacher 2007). In MAUT, the perceptors are criteria of evaluation (e.g., economy, ecology, etc.) as presented in Fig. 9, and they are often based on subcriteria of evaluation. There are different ways in which the criteria and subcriteria (which are the cues of evaluation) may be linked or how a comparative evaluation may be conducted. In addition to "weighing and summing" (i.e., a linear model application), there are other approaches (Saaty 1990). We previously stressed that we go beyond the linear model (bootstrapping) interpretation of Brunswik's Lens Model and argue that, in addition, nonadditive, nonlinear methods may be applied (see next paragraph). The "best" (i.e., most sustainable) solution can also be achieved by lexicographically ordering different evaluation criteria, and then selecting-in pairwise comparison-the alternative that shows superiority on the most important evaluation criterion, where one can discriminate between the criteria (this corresponds to a kind of searching and stopping rule; see, e.g., Gigerenzer and Kurz 2001).

The MAUT-based (mean) evaluations of different stakeholder groups can also be conceived as perceptors. Thus, TPF principles can be applied in methods of interest x stakeholder analysis (Bryson 2004; Islam and Susskind 2012; Reed et al. 2009). The right side of the lens, then, can represent a negotiation and sometimes even a consensus- 

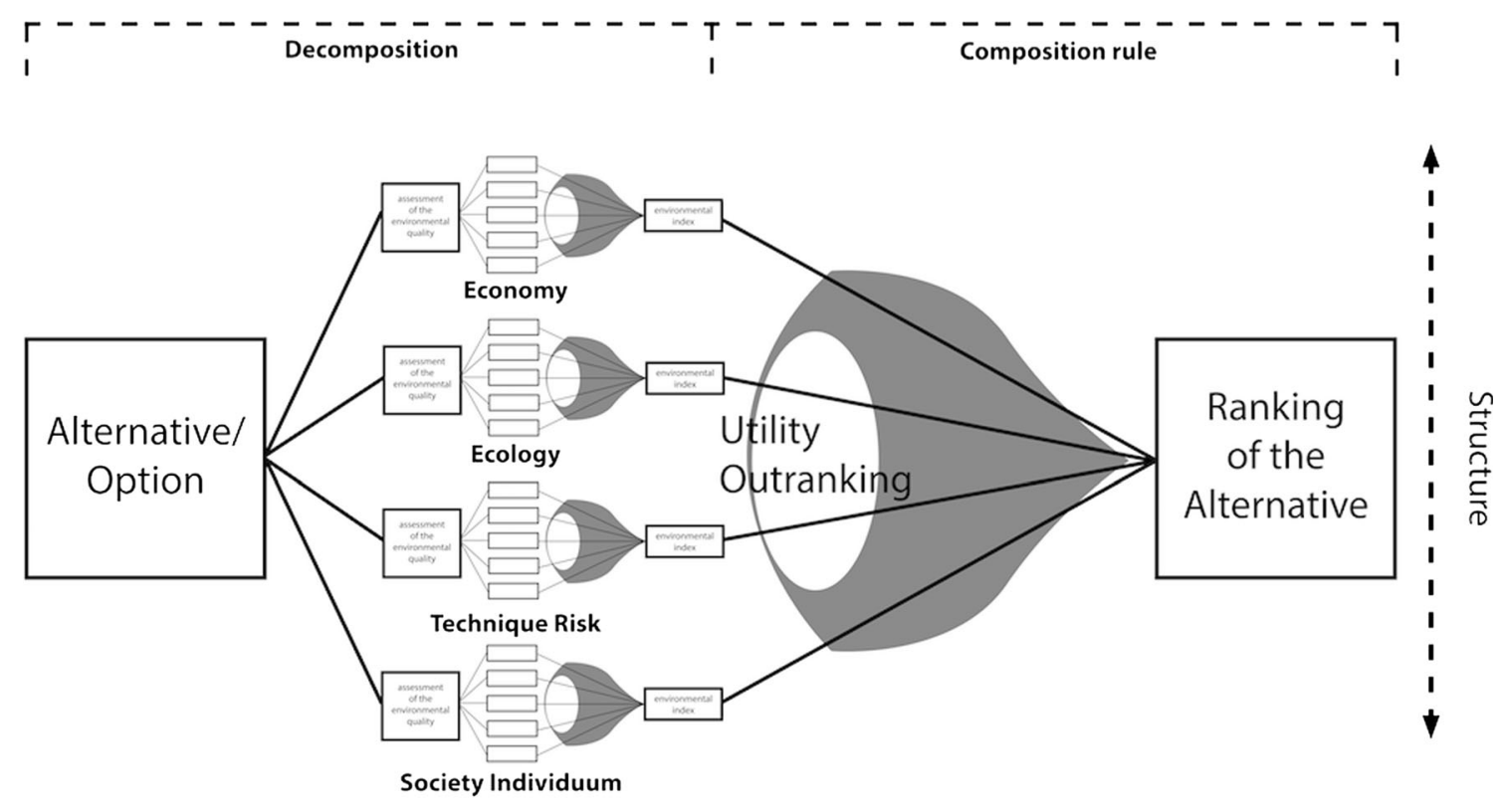

Process

Fig. 9 The Brunswikian Lens Model for multi-attribute utility theory

building process (Loukopoulos and Scholz 2004; Susskind et al. 2000).

\subsubsection{TPF principles as properties of sustainability planning}

In the last section, we started from planning processes and described aspects according to the TPF. Now we shift our perspective and utilize TPF principles to describe how well-functioning sustainability planning group should work. This turns the descriptive perspective in a prescriptive perspective or even a normative perspective (Baron 2004). The second column of Table 1 summarizes what has been presented in the first sections on visual perception. When conceiving planning groups as organisms, Column 3 sketches properties of sustainable planning based on TPF principles. From a prescriptive perspective, the sketched properties can be used as guidelines for planning groups. The right-hand column in Table 1 presents various causes of planning groups' malperformance as a result of not following TPF principles. This may confirm or supplement scientific (Belsky et al. 2013; Dörner and Schaub 1994; Swenk 1999) and practitioners' guides for avoiding planning errors. From a normative perspective, i.e., when postulating that the TPF principles are general rules, the question of how this can be verified emerges. This is the subject of the next section.

\section{Validation of applications of the Theory of Probabilistic Functionalism}

\subsection{Model validity of the regression-based Lens Model}

There are many different concepts of validation. We first deal with model validity referring to the regression-based Lens Model. In perception, Brunswik focused on ecological validity as the accuracy of the cues sampled by the perceptors $x_{1}, \ldots, x_{k^{\prime}}, \ldots x_{k}$. Ecological validity assesses how well the proximal cues represent the environmental, actuarial, factual, real-world information and not how the findings may be transferred to other settings, situations, or cases, etc. (i.e., external validity). If we were to assume that the reality works (as an intuitive "frequency statistician" along the linear model with multiple judgments), actual validity is assessed by correlations $\left(r_{1_{e}}, \ldots, r_{k_{e}^{\prime}}, \ldots, r_{k_{e}}\right)$ between an environmental, actuarial value $Y_{e}$ and cue values and the perceptors (see Fig. 10).

For perception, the upper left-hand box of Fig. 10 represents properties of a physical object of the environment $Y_{e}$. We may take as an example the weight of a bear or a $\operatorname{dog}\left(Y_{e}\right)$, which is a good proxy for potential danger that you may unexpectedly encounter on a hiking trip. Then the proximal information is processed and integrated to a decision maker's or subject's $(S)$ actuarial judgment $\left(Y_{S}\right)$. This description of validity is referring to an assumed real process to which we have-unfortunately-only an 
Fig. 10 The validation problem in the individual perception (and judgment) paradigm of TPF The shaded area represents the theoretical and model of the perception judgment (upper lens; taken from Scholz and Tietje 2002, p. 340)

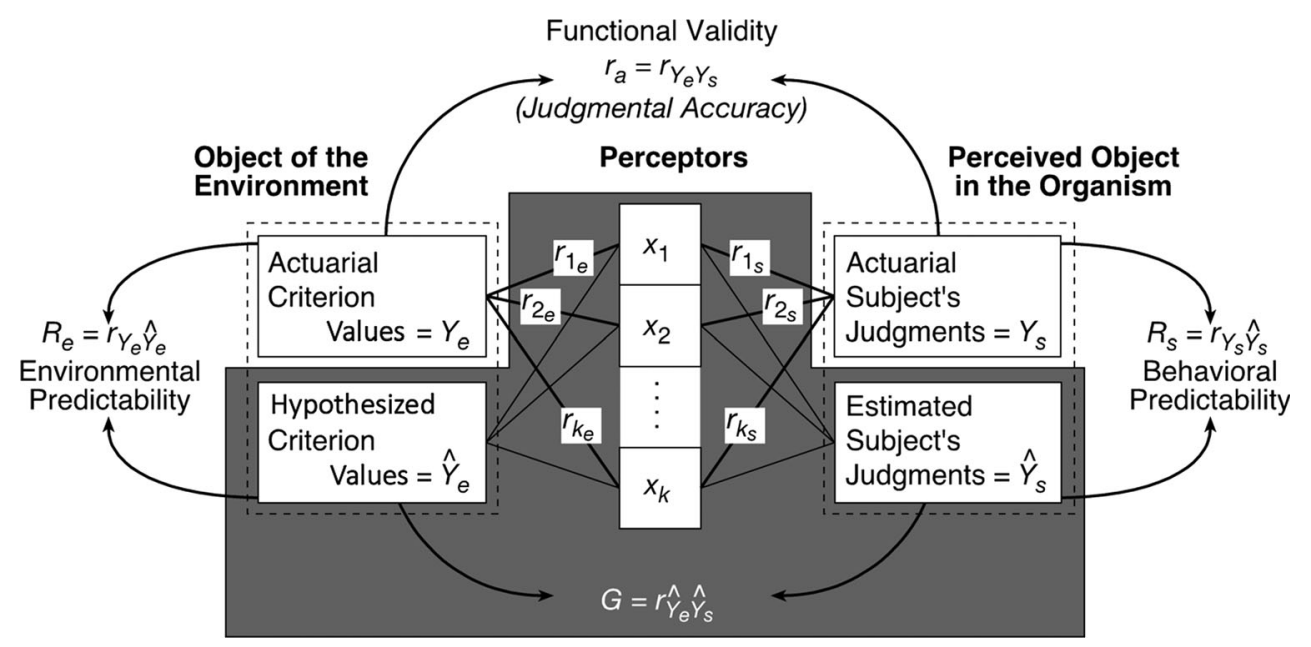

unlimited process. This reality is accessible only by modeling and data/observations (which may be used for testing a model; see the lower part of Fig. 10). The scientist works with a measured or estimated actual criterion value $\left(\hat{Y}_{e}\right.$, see lower part of Fig. 10). If we face multiple judgments $Y_{S}$, the correlation between the real, actuarial, and measured values $\hat{Y}_{e}$ and model-based estimates $\hat{Y}_{e}$ of subjects may be represented by correlations $\left(R_{e}=r_{Y_{e}, \hat{Y}_{e}}\right)$ or other indicators. We may call this behavioral environmental predictability or model validity.

This reality is accessible only by modeling and data/ observations (which may be used for testing a model; see the lower part of Fig. 10). The scientist works with a measured or estimated actual criterion value $\left(\hat{Y}_{e}\right.$, see lower part of Fig. 10). If we face multiple judgments $Y_{S}$, the correlation between the real, actuarial, and measured weight $Y_{e}$ and model-based estimates $\hat{Y}_{e}$ of subjects may be represented by correlations $\left(R_{e}=r_{Y_{e}, \hat{Y} e}\right)$ or other indicators. We may call this behavioral environmental predictability, evidence-based accuracy of a model or model validity.

\subsection{Validating sustainable planning group action}

Figure 11 provides the same structure for sustainable transitioning. We use the term "case" for the system that is of interest. As sustainability is a complex issue, we do not expect to (just) get one real number for an estimate of the current level of sustainability, although we want to mention that there are (comprehensive) LCA scores (Friedrich et al. 2007), resilience or adaptive capacity scores (National Research Council 2015; Scholz 2017a; Scholz et al. 2012), and sustainability indices (Böhringer and Jochem 2007; Mori and Christodoulou 2012; Morse 2015) as quantitative parameters (see Fig. 11).
Let us refer to the example of assessing the sustainability of a future scenario. Besides the "quantitative sustainability" indicators, we suggested benchmarking by "best practices cases" and expert evaluations (see above). The properties of a planning scenario can be usefully compared to "best practices cases." However, this would call for constructing a design for validating whether the scenario (Box 1, Step 3), the criteria of sustainability evaluation (Step 4), and the strategies recommended are "evolutionarily appropriate." Note that from a sustainability perspective, not only the properties of a future state but also the impact of a sustainable planning team's model on future developments (e.g., whether on decision makers' preferences or actions) can be measured. Such evaluations are difficult, as each region or case is unique (and, thus, there is no option for a traditional statistical design), and single case pre-post, post hoc, or comparative studies are also too difficult. Although we have long known that the "evaluation of planning is problematic" (Hogarth and Makridakis 1981, p. 116), the difficulties and perhaps even the lack of validation of planning is a peril for not developing sustainably (see Table 1, last column, P6).

\subsection{Gentle verification of TPF and its principles}

The most significant methodological challenge, without a doubt, is the validation of TPF. Let us distinguish between content validity and construct validity. Simplified, content validity aspires to identify and to assess criteria (i.e., types of observational data) which prove that TPF principles underly the operations of planning groups when constructing a (real) sustainable planning variant. This is utmost difficult if not impossible. Construct validity is easier and has been provided, in part, by Adelman et al. (2003) when testing whether variations of environmental (independent) variables induce variations of group performance in line with the rationale of the TPF principles. The 
Fig. 11 The validation problem for sustainable transition studies. The boxes on the left represent the case, e.g., a city, region, and country; those on the right represent the transition of the case. The shaded area displays the study team's activity or projection into the future. The upper lens represents either the best possible projection (as a benchmark) or (in a postcomparison) the development a case could have taken

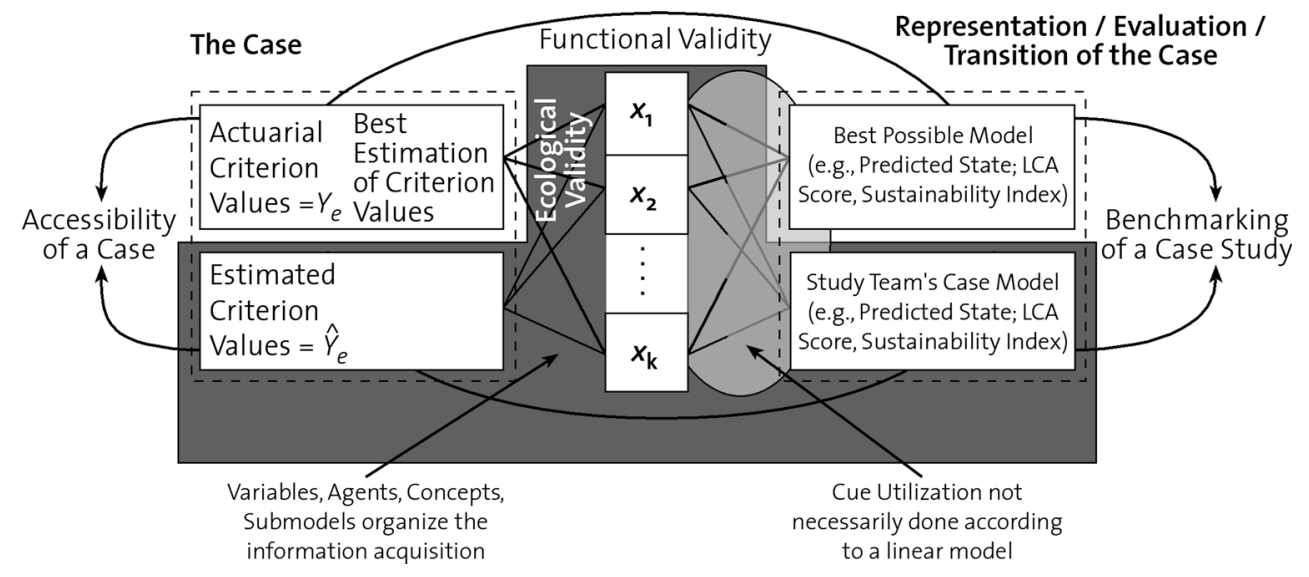

challenge is to design experiments or surveys that provide data allowing an assessment of whether or not and how much what (aspect[s]) of TPF principles are inherent in a specific group's behavior. Such a process (though expensive) does not allow for direct positivist testing by falsification (as any model testing). Reference has to be taken from different studies and findings. Thus, "gentle verification" and not positivist testing may take place.

In addition, the question about whether TPF is right or wrong cannot be answered. This holds true for any important theory such as Darwin's Theory of Evolution, which may be viewed as a metatheory or framework. However, we may well imagine that we can run an experiment with planning groups (of master students) and continuously monitor whether or not a particular TPF principle is at work, and then relate this to the results of the groups. We may also, alternatively, think about training groups in TPF principles and let them benchmark (continuously) their accordance with these principles. This can be compared with control groups. This is theory and has not been done in any of the above-mentioned studies. However, we can approach some level of validation, for instance, if we notice that sustainable planning is lacking a theoretical foundation for "developing socially robust orientations for sustainability" (see Scholz 2011, pp. 378-379) and feel that TPF may contribute to this deficiency.

\section{Discussion and conclusions}

\subsection{The Theory of Probabilistic Functionalism as a general theory of perceptual and cognitive complexity management in inextricably coupled organism-environment systems}

Egon Brunswik developed the TPF about 75 years ago to answer the question of how organisms perceive reality given the complexity of environmental information. Human visual perception has been Brunswik's experimental showcase. His psychological and epistemological approach was labeled the science of objective relations. Thus, Brunswik strongly emphasized evolutionary, adaptive processes. Perception was seen as a main link between the environment and human action. As such, TPF may be seen as the cradle of research on coupled human and environmental systems.

We have presented and discussed the basic epistemological and ontological principles of Brunswik's comprehensive, groundbreaking theory. We have discussed the concept that the group - as a human system above the level of the individual—can be considered an organism and a functional unit, both from a biological and cognitive psychology (and presumably also behavioral) perspective (Wilson and Sober 1994). Brunswik considered the organism and the environment as inextricably coupled and stressed the different rationales of human and environmental systems. This conception of a coupled system has gained increasing attention in the last decade (Scholz 2011).

Brunswik introduced the well-known Lens Model and the key relationships/principles in one of his later books (Brunswik 1952) without a specific operationalization. Thus, the TPF principles (see Table 1) may be regarded as general principles of the organism's complexity management. For instance, functionalism is a general assumption that organismic behavior (and entities such as organs) are purposeful and can only be understood according to their functional roles (Levin 2013). Based on the analysis of this paper, we think that the principles of the TPF (such as the probabilistic sampling of cues) have the same status as Darwin's basic evolutionary principles (Mayr 1998) or adaptation (Hulburt 2002). Both TPF and evolution theories describe basic rules of natural order. Darwin's principles deal with "biological complexity," variation, and development (Bard 2016). The subject of TPF principles is 
the organism's successful interaction with the environment. Darwin's principles are independent of species, scale, etc. This may also hold true for the TPF, as the concept of organism is a nexus concept that refers to human systems below and above the level of the individual.

We have stressed repeatedly in various section of this paper that the reduction to a weighting by linear-regression-based Lens Model is only one option for operationalization. Linear regression modeling works well in some cases and may continue to be a valued model of social judgment (Hammond and Stewart 2001). The TPF allows for different (nonparametric) modeling approaches, as suggested, e.g., by Gigerenzer and Kurz (2001). The principles of the TPF did not emerge from the linear regression model and do not refer to a specific physiological process.

\subsection{The TPF principles align closely with current physiological approaches to sensation and perception}

Section 3 provides an in-depth analysis of the principles of the TPF in light of contemporary conceptions of visual perception. This analysis shows that the TPF provides a valuable framework for understanding and explaining the multitude of processes involved in contemporary biophysical models of visual perception. Based on experimental results on the processing of stimuli at the level of rods and cones, the interaction among perceptors has been identified as another, seventh principle (P7) of TPF.

The visual system is a highly complex one and, presumably, the most important of the human senses. The eye is related to the neural system and the brain. In the brain, i.e., the visual cortex and hippocampus, the signals produced by neurons of the eye, etc. are integrated for seeing. They comprise 30\% of the cortex (Kozma et al. 2004), whereas hearing comprises only 3\% (Grady 1993). Brunswik distinguished between bottom-up (environmental), stimuli-driven processes that emerge from distal stimuli perceived by the sensory system and (proximal) representations and processes of the perceptors. For bottom-up processes, perceptual salience is essential. It is interesting to see that Brunswik's idea of the psychology of objective relations and representative design appear just at this point: "..., in real life, the salience of objects is strongly related by the behavioral relevance" (Corbetta and Shulman 2002, p. 207). Cognitive salience is acquired by learning or is hardwired. The latter has been demonstrated by studies showing that the perception of spiders and snails is evolutionarily primed. Spiders and snails are cues (i.e., danger signals) that elicit different psychophysical processes (underlying anxiety) in males and females (Fox et al. 2007).
Therefore, the ecological rationality (related to representativeness; P5) of the eye and what is considered the natural environment has an evolutionary and an experiential (sociocultural) foundation. A sociocultural dimension enters functionality (P1) if "the usefulness of an item or activity depends ... on how it is understood and valued from a socially and historically contingent system of symbols" (Hutson and Stanton 2007, p. 123). The Eskimos, for instance, have traditionally used 160 different terms for snow, and it is unthinkable that they could have efficiently communicated information about the different types and functions of snow using a single term (Martin 1986; Whorf 1956). Moreover, this example demonstrates the importance of both the environmental, material, and biophysical aspects of the initial focal variable and the sociocultural and epistemic side of human-environment interaction. The evolutionary, biological, stimulus-driven side component has been demonstrated by Heider-Rosch (1971). She conducted a groundbreaking study in which she showed that the Dani, an ethnolinguistic group of Irian Jaya, focus (proto)typical colors of the Munsell color system, although they have never seen colors before (Berlin and Kay 1969). This would be an example of stimulus-driven salience. We can learn from this that the universality of salient color variants as a bottom-up process is linked to the top-down process of culturally acquiring functional color labels that differ among regions (Kay and Regier 2007). Or to express it in other terms, visual perception has generic (evolutionary) and specific (cultural) components.

\subsection{The TPF and planning groups' work for sustainable development}

There are essential differences between visual perception and planning group activities. The human eye has evolved in the course of human evolution. Its current state is a product of mutation and evolutionary selection that has developed on a biological (or even geological) time scale. Whether a certain mutation of the eye is evolutionarily successful is a matter of tens of thousands of years and more. Sustainability planning is related to historical timeframes and has a completely different nature; it is not governed by homeostatic processes of regulation. Whether a planning team will survive is a matter of the market (1-10 years). Whether a proposed plan will have an (measurable) effect is a matter of the next several decades. Yet planning groups have functions and serve purposes (P1) such as creating "socially robust orientation for sustainable transitioning" (Gibbons and Nowotny 2001). A planning group is competing with other groups, and when referring to the nexus concept of organisms, we suggest that sustainability planning groups follow basic rules (i.e., trajectories) of (co)operation and functioning. The question 
to be answered is whether TPF is a proper framework for describing and representing these basic rules.

\subsubsection{TPF is a tool for describing operations of sustainable planning groups}

Based on the experience gained in multi-year practice with about 100 temporary planning groups working on sustainable transitioning of urban and regional systems, industrial branches, policy processes, and (global) biogeochemical cycles (Scholz et al. 2006), we presented typical steps of planning groups (Box 1) and could-in a first step-illustrate how the TPF principles are involved in key aspects of sustainable planning (see 4.2).

The principles of TPF are a wonderful tool or "integration device” (Hammond et al. 1980, p. 8) for describing essential processes of sustainable planning groups. There is no doubt that essential properties of the main steps of planning (see Box 1) can be described and analyzed by the TPF principles. For Step 1, problem definition and goal formation, referring to P1 (Functionalism) and P6 (Evolutionary Stabilization), are essential. In Step 2, case selection and system representation/scenario construction stress the analysis of the environment and take a coupled humanenvironment view (as included in P2) and acknowledge probabilistic data (cue) acquisition (i.e., P4, vicarious mediation). The substitutability of missing data, stakeholders, etc. in case projecting and system representation/constructing of planning alternatives also refers heavily to P4. Here the interlinkage of perceptors (P7) as an uncertainty-causing source (P3) in coupled human-environment systems is key for planning. Likewise, the evaluation has to follow these principles whereupon, according to P2 (i.e., when acknowledging the rationale and drivers of the different environmental system) plays an important role. Finally, in Step 5, the construction of socially robust solutions/orientations meets the core of P6, the evolutionary stabilization principle. How this may look in detail can be taken from Table 1, Column 4.

This shows that the TPF principles provide something like a set of tools that may well describe the core activities of sustainable planning groups. We also showed how the application of methods such as FSA for the construction of planning variants/scenarios or the evaluation of scenarios by means of MAUT could be well framed by the TPF principles. This type of descriptive analogy building between cognitive and brain functions and structuring groups decision making has been followed also by Linkov et al. (2012).

\subsubsection{TPF principles can be used as prescriptive tools}

Planning for sustainability is one of the most challenging cognitive and social undertakings. Planning teams have to cope with long time ranges and multiple uncertainties of complex, coupled, multi-level, highly interacting, coupled human-environment systems. There is a need for approaches that help to structure and to reduce complexity which can be seen as a task of "adaptive functional psychology" (Kirlik 2006a, p. 3). We suggest that the presented principles of TPF be used for this. The fourth column of Table 1 may serve not only as a descriptive but also as a prescriptive tool. The TPF principles may serve as a reference for how a successful planning group can cope with environmental complexity in the frame of evolutionary stabilization.

Thus, the principles of TPF have the potential to serve as a prescriptive reference. When referring to Fig. 2 and the last columns of Table 1 , the following questions can be answered:

- Do we focus on the right goals (i.e., is the terminal focal variable well chosen), and does the system that is investigated or do we, in the case of sustainable transitioning, look at the right issues (i.e., is the initial focal variable properly chosen) for the function of interest (see P1, Functionalism)?

- Do we sufficiently acknowledge the uncertain, probabilistic cue acquisition and cue processing of the perceptual system, a sustainability planning team, etc.? Is the cue sampling robust enough in the sense that the result (i.e., the terminal focal variable) is sufficiently robust if single cues are not available or overly biased (see P3, Probabilistic information acquisition and processing)?

- Do we sufficiently consider the interaction of the perceptors (i.e., the receptors in case of perception) or the subsystems (in case of sustainable transitioning) (see P7, Interlinkage of perceptors)?

- Are the results of the perceptional and judgmental process or the sustainable planning team sufficiently good and do they make the system sufficiently resilient, thus helping to reduce critical vulnerabilities (see P6, Evolutionary stabilization)?

- Is the system chosen (i.e., the initial and terminal focal variable) sufficiently representative for the perceptual system, judgmental process, or sustainable transitioning, or are we studying some idiosyncratic, artifactual system (see P5, Representative design)?

- Do we sufficiently acknowledge the rationale and constraints of environmental systems and of human systems if we look at the perceptual achievement or sustainable transitioning (see P2, Dualism)? 
Most of these questions include a metaphysical and a pragmatic perspective in the sense of approaching a "workable concept of mind" (Kirlik 2006a, p. 5). The metaphysical view helps us to understand the nature of what is investigated, e.g., of what makes sustainable development. We think that the present discussion can be well related to management and planning science (Friend and Hickling 2005; Gregory et al. 2012; Healey 2009). The pragmatic perspective helps us to apply methods and knowledge in a meaningful, functionalist way. Therefore, the questions may serve as a kind of logbook for the research of complex issues.

A key challenge of the prescriptive perspective is the terminal focal variable, i.e., what is considered to be the (future) state or criteria, e.g., of sustainable cities. We have argued that, despite the ill-defined and tremendous uncertainties involved in sustainable transitioning and the fuzziness of sustainability, there is emerging (and quantifiable) knowledge (e.g., in resilience research) about what makes systems sustainable. We suggested benchmarking by best practices, reference to sustainability indicators, and expert judgments as means for defining proper goals and launching some kind of "evolutionary stabilization."

We want to emphasize that, for providing meaningful orientations (or benchmarks) for sustainable development, comprehensive literacy about the real-world system and about system science is needed. For gaining insights into the functioning of real-world systems, scientists are asked to come down from their ivory towers (see Sect. 4.1.2). For developing or implementing representative designs as sustainable planning variants, it is meaningful or necessary to include (experienced) practitioners, as is characteristic for transdisciplinary planning processes (Scholz and Steiner 2015a). This allows for properly identifying the important cues that are relevant for accepting and implementing sustainable technologies. For instance, energy planners of South African township of Elkani had to learn that "solar technology" is linked with the (sociocultural) image (cue, sign, symbol) of being the "energy of the poor man" and, as such, had a tendency to be fundamentally rejected (van Breda 2014). Thus, a sociocultural barrier related to the "natural environment of the users" (P5) was ignored.

Another necessity is a high rate of literacy in systems science, which is needed in sustainable planning. In order to show how TPF can contribute, let us briefly refer to a common violation of the representativeness logic (P5). A common error of planning that may be avoided here is the ceteris paribus principle of planning (Girod et al. 2011). Manipulating just one variable (e.g., the price of one mineral) while leaving the others (e.g., prices of other minerals) unchanged is unrealistic for an environmental impact assessment. We have to opt for a "business-as- usual" logic, i.e., to a world which is natural (representative) for the user. The money saved will be spent on other items (e.g., for travel) that may cause even greater environmental impacts.

\subsubsection{TPF as a nomothetic, ontological framework?}

When utilizing TPF for sustainable planning, we may ask about the epistemological and/or ontological status. We can argue that the description of planning groups was based on a suggested likeness, i.e., a metaphorical analogy, between visual perception and planning groups. When we move to a prescriptive perspective, rules, directions, criteria, and more or less precise instructions are provided. In this case, we may talk about an epistemological level of consideration as we refer to recognized, established, longstanding standards of good planning. Therefore, a prescription can be drawn from a pragmatic, engineering-like perspective. However, we have even suggested that Brunswik's TPF principles are of an ontological nature. TPF describes fundamental rules and mechanisms of the organism's interaction with the environment in the way that Darwin's theory describes the development and order of nature. The transfer of TPF from visual perception to planning groups was based on the nexus concept of organisms.

Ontological assumptions such as Darwinian principles are an ongoing matter of scientific discussion. They include basic cosmological assumptions about how reality or how the world is becoming, being, and functioning. The history (of science) has shown that the acceptance or denial of ontological assumptions strongly depends on whether they can meaningfully frame relevant evidence or whether they cause unwanted contradictions. Thus, for instance, functionalist ontology (as one component of TPF)—such as many ontological assumptions - cannot be validated or disproved. Simplified, the acceptance of ontological assumptions depends on whether they are believed and whether they make sense in light of what we know, experience, and value to be meaningful. This leads us back again to the questions of the validation of TPF and whether or not and how it can be used.

\subsection{The challenge of valuation and the future use of TPF}

In line with the message "There is nothing more practical than a good theory," we think that Brunswik's idea may still be of the highest scientific relevance and has the potential to help us better understand how human systems can meaningfully cope with complexity if an evolutionary or developmental perspective is taken. The application of TPF for planning groups' construction of sustainable future 
scenarios may open the door for a better description and deeper understanding of planning groups' meaningful coping with sustainable transitioning, a major challenge for both science and society. We have shown that, for all the ways TPF can be used, i.e., in a descriptive, prescriptive, and normative way, the challenge of validation is imperative. We sketched that the impacts of (following) certain aspects of TPF principles or of not following them can be investigated in experimental settings. This is one component of gentle verification. In addition, the presented power of the principles of TPF for describing the biophysical processes of the eye can be considered another piece. This at least holds true if we conceive gentle verification as the use of multiple evidences and methods (some of them with moderate causal strength) that provide evidence and/or insight into the validity and usefulness of a theory. Thus, it is our hope that the present paper has gone beyond outlining the potential for Brunswik's TPF to offer an important theoretical pillar for understanding planning groups' activities. We further hope that the methodological discussion, in particular about validating the TPF, has motivated researchers to initiate real-world research (e.g., on sustainable planning groups) in order to better understand the foundations of decision making in sustainable transitioning.

Acknowledgements Open access funding provided by Danube Universtity Krems University for Continuing Education. Many thanks to the ten ES\&D reviewers and to Berhard Geissler, Eva Schernhammer, Gerald Steiner, Günther Schreder, and many others who provided important, challenging, and inspiring feedback to a previous version of this paper and to all others who provided seminal inputs in the long course of writing this paper. Thanks to Sandro Bösch and Georg Neubauer for editing the figures and to Elaine Ambrose who assisted in improving the English and the understandability of this manuscript. Special thanks to Markus Heindl who helped me to cope with the amazing imponderabilites of the EndNote program at a critical stage in the production of this paper.

Open Access This article is distributed under the terms of the Creative Commons Attribution 4.0 International License (http://crea tivecommons.org/licenses/by/4.0/), which permits unrestricted use, distribution, and reproduction in any medium, provided you give appropriate credit to the original author(s) and the source, provide a link to the Creative Commons license, and indicate if changes were made.

\section{References}

Adelman L, Miller SL, Henderson D, Schoelles M (2003) Using Brunswikian theory and a longitudinal design to study how hierarchical teams adapt to increasing levels of time pressure. Acta Physiol (Oxf) 112(2):181-206

Adelman L, Miller SL, Yeo C (2004) Testing the effectiveness of icons for supporting distributed team decision making under time pressure. IEEE Trans Syst Man Cybern A Syst Hum 34(2):179-189
Bard J (2016) Principles of evolution: systems, species, and the history of life. Garland Science, New York

Barlow HB (1972) Single units and sensation: a neuron doctrine for perceptual psychology? Perception 1(4):371-394

Baron J (2004) Normative models of judgment and decision making. In: Koehler DJ, Harvey N (eds) Blackwell handbook of judgment and decision making. Blackwell, Malden

Batan M, Butterfoss F, Jaffe A, LaPier T (2011) A sustainability planning guide for healthy communities. US Dept of Health and Human Services, Centers for Disease Control and Prevention, Atlanta, GA

Bell S, Morse S (2008) Sustainability indicators: measuring the immeasurable? Earthscan, London

Bell S, Morse S (2013) Measuring sustainability: learning from doing. Routledge, London

Belsky ES, DuBroff N, McCue D, Harris C, McCartney S, Molinsky J (2013). Advancing inclusive and sustainable urban development: Correcting planning failures and connecting communities to capital. Joint Center for Housing Studies at Harvard University, Cambridge, MA

Berlin B, Kay P (1969) Basic color terms: their universality and evolution. University of California Press, Berkeley

Berry MJ II, Brivanlou IH, Jordan TA, Meister M (1999) Anticipation of moving stimuli by the retina. Nature 398(6725):334

Binder CR, Hinkel J, Bots PWG, Pahl-Wostl C (2013) Comparison of frameworks for analyzing social-ecological systems. Ecol Soc. doi:10.5751/es-05551-180426

Birnbaum MH, Wong R, Wong LK (1976) Combining information from sources that vary in credibility. Mem Cognit 4(3):330-336

Böhringer C, Jochem PEP (2007) Measuring the immeasurable-a survey of sustainability indices. Ecol Econ 63(1):1-8

Bose U (2015) Design and evaluation of a group support system supported process to resolve cognitive conflicts. Comput Hum Behav 49:303-312

Brehmer B (1976) Social judgment theory and the analysis of interpersonal conflict. Psychol Bull 83(6):985-1003

Brehmer B (1988) The development of social judgment theory. Adv Psychol 54:13-40

Brehmer B, Hagafors R (1986) Use of experts in complex decision making: a paradigm for the study of staff work. Organ Behav Hum Decis Process 38(2):181-195

Brewer P, Venaik S (2014) The ecological fallacy in national culture research. Organ Stud 35(7):1063-1086

Bruce CJ, Friedman HR (2002) Eye Movements. In: Ramachandran VS (ed) Encyclopedia of the human brain. Elsevier, Dordrecht, pp 269-297

Brunswik E (1933) Die Zugänglichkeit von Gegenständen für die Wahrnehmung und deren quantitative Bedeutung [The accessibility of objects for perception and their quantitative meaning]. Archiv für die gesamte Psychologie 88:377-418

Brunswik E (1936) Psychologie vom Gegenstand her [Psychology in terms of the object]. In: Congress board of the international congress of philosophy (Ed) Congrès International de Philosophie à Prague, 2-7 Septembre 1934 [Documents of the eighth international congress of philosophy at Prague, 2-7 September 1934]. Orbis, Prag, pp 840-845

Brunswik E (1937) Psychology as a science of objective relations. Philos Sci 4(2):227-260

Brunswik E (1939) Probability as determiner of rat behavior. J Exp Psychol 25:175-197

Brunswik E (1940) Thing constancy as measured by correlation coefficients. Psychol Rev 47:69-78

Brunswik E (1943) Organismic achievement and environmental probability. Psychol Rev 50(3):255-272

Brunswik E (1946) Points of view: Components of psychological theorizing. In: Harriman PL (ed) Encyclopedia of psychology. 
Carol Publishing Group: Philosophical Library, New York, pp 532-537

Brunswik E (1952) The conceptual framework of psychology. University of Chicago Press, Chicago

Brunswik E (1955) Representative design and probabilistic theory in a functional psychology. Psychol Rev 62(3):193-217

Brunswik E (1956) Perception and the representatve design. Design of psychological experiments. University of California Press, Berkeley

Brunswik E (1957) Scope and aspects of the cognitive problem. In: Gruber H, Hammond KR, Jessor R (eds) Contemporary approaches to cognition. Harvard University Press, Cambridge, pp 41-69

Bryson JM (2004) What to do when stakeholders matter. Stakeholder identification and analysis techniques. Public Manag Rev 6(1):21-53

Busch P, Heinonen T, Lahti P (2007) Heisenberg's uncertainty principle. Phys Rep Rev Sect Phys Lett 452(6):155-176. doi:10. 1016/j.physrep.2007.05.006

Camerer C (1981) General conditions for the success of bootstrapping models. Organ Behav Hum Perform 27(3):411-422. doi:10. 1016/0030-5073(81)90031-3

Cohen IR (2000a) Discrimination and dialogue in the immune system. Semin Immunol 12(3):215-219

Cohen IR (2000b) Tending Adam's garden: evolving the cognitive immune self. Academic Press, London

Corbetta M, Shulman GL (2002) Control of goal-directed and stimulus-driven attention in the brain. Nat Rev Neurosci 3(3):201-215. doi:10.1038/nrn755

Cosmides L, Tooby J (1996) Are humans good intuitive statisticians after all? Rethinking some conclusions from the literature on judgment under uncertainty. Cognition 58(1):1-73. doi:10.1016/ 0010-0277(95)00664-8

Curcio CA, Sloan KR, Kalina RE, Hendrickson AE (1990) Human photoreceptor topography. J Comp Neurol 292(4):497-523

de França Doria M, Boyd E, Tompkins WL, Adger WN (2009) Using expert elicitation to define successful adaptation to climate change. Environ Sci Policy 12(7):810-819

Dhami MK, Olsson H (2008) Evolution of the interpersonal conflict paradigm. Judgm Decis Mak J 3(7):547-569

Dhami MK, Hertwig R, Hoffrage U (2004) The role of representative design in an ecological approach to cognition. Psychol Bull 130(6):959-988. doi:10.1037/0033-2909.130.6.959

Doherty ME, Kurz ME (1996) Social judgement theory. Think Reason 2(2):109-140

Doherty ME, Tweney RD (2004) Reasoning and task. In: Manktelow K, Chung MC (eds) Psychology of reasoning: theoretical and historical perspectives. Taylor and Francis, Hove, pp 11-41

Dörner D, Schaub H (1994) Errors in planning and decision-making and the nature of human information processing. Appl Psychol 43(4):433-453

Dunwoody PT (2009) Theories of truth as assessment criteria in judgment and decision making. Judgm Decis Mak 4(2):116-125

Fischer KR, Stadler F (eds) (1997) "Wahrnehmung und Gegenstandswelt": Zum Lebenswerk von Egon Brunswik (1903-1955) [Perception and world of objects: On the lifework of Egon Brunswik (1903-1955)]. Springer, Vienna

Fodor JA (1981) The mind-body problem. Sci Am 244(1):124-132

Foley E (2014) Sustainability planning guidebook for teams. Retrieved from Pennsylvania

Fox E, Griggs L, Mouchlianitis E (2007) The detection of fearrelevant stimuli: are guns noticed as quickly as snakes? Emotion 7(4):691-696. doi:10.1037/1528-3542.7.4.691

Friedrich E, Pillay S, Buckley C (2007) The use of LCA in the water industry and the case for an environmental performance indicator. Water Sa 33(4):443-452
Friend J, Hickling J (2005) Planning under pressure. The strategic choice approach. Elsevier, Amsterdam

Gibbons M, Nowotny H (2001) The potential of transdisciplinarity. In: Thompson Klein J, Grossenbacher-Mansuy W, Häberli R, Bill A, Scholz RW, Welti M (eds) Transdisciplinarity: joint problem solving among science, technology, and society. An effective way for managing complexity. Birkhäuser, Basel, pp 67-80

Gifford R (1994) A lens-mapping framework for understanding the encoding and decoding of interpersonal dispositions in nonverbal behavior. J Pers Soc Psychol 66(2):398-412. doi:10.1037/00223514.66.2.398

Gigerenzer G (1997) Ecological intelligence: an adaption for frequencies. Psychologische Beiträge 39:107-125

Gigerenzer G, Kurz EM (2001) Vicarious functioning reconsidered: a fast and frugal lens model. In: Hammond KR, Stewart TR (eds) The essential Brunswik. Beginnings, explications, applications. Oxford University Press, New York, pp 342-347

Gigerenzer G, Murray DJ (1987) Cognition as intuitive statistics. Erlbaum, Hillsdale

Girod B, de Haan P, Scholz RW (2011) Consumption-as-usual instead of ceteris paribus assumption for demand-integration of potential rebound effects into LCA. Int J Life Cycle Assess 16(1):3-11

Glöckner A, Betsch T (2012) Decisions beyond boundaries: when more information is processed faster than less. Acta Physiol (Oxf) 139(3):532-542

Goldstein WM (2006) Introduction to Brunswikian theory and method. In: Kirlik A (ed) Adaptive perspectives on humantechnology interaction. Methods and models for cognitive engineering and human-computer interaction. Oxford University Press, Oxford, pp 10-24

Goldstein WM, Hogarth RM (1997) Judgment and decision research: Some historical context. In: Goldstein WM, Hogarth RM (eds) Reserach and judgement and decision making: currents, connections, and controversies. Cambridge University Press, Cambridge, pp 3-68

Gollisch T, Meister M (2008) Rapid neural coding in the retina with relative spike latencies. Science 319(5866):1108-1111

Grady D (1993) The vision thing: mainly in the brain. Discover (June $01)$

Green DM, Swets JA (1966) Signal detection theory and psychophysics. Wiley, New York

Gregory R, Failing L, Harstone M, McDaniels T, Ohlson D (2012) Structured decision making. A practical guide to environmental management choices. Wiley, Chichester

Gross CG (2002) Genealogy of the "grandmother cell". Neuroscientist 8(5):512-518

Hamm RM, Yang HQ (2017) Alternative lens model equations for dichotomous judgments about dichotomous criteria. J Behav Decis Mak 30(2):527-532. doi:10.1002/bdm.1969

Hammond KR (1954) Representative vs. systematic design in clinical psychology. Psychol Bull 51:150-159

Hammond KR (2000) Human judgment and social policy: irreducible uncertainty, inevitable error, unavoidable injustice. Oxford University Press, Oxford

Hammond KR (2001) Scope and aspects of the cognitive problem [1957]. Comment. Last words. In: Hammond KR, Stewart TR (eds) The essential Brunswik. Beginning. Explications, applications. Oxford University Press, Oxford, pp 298-300

Hammond KR (2006) Foreword. In: Kirlik A (ed) Adaptive perspectives on human-technology interaction. Methods and models for cognitive engineering and human-computer interaction. Oxford University Press, Oxford, pp 7-10

Hammond KR, Brehmer B (1973) Quasi-rationality and distrust: Implications for international conflict, Human Judgment and 
Social Interaction. In: Rappoport L, Summers DA (eds) Human judgment and social interaction. Holt, Rinehart and Winston, New York

Hammond KR, Stewart TR (eds) (2001) The essential Brunswik. Beginning, explications, applications. Oxford University Press, Oxford

Hammond KR, Stewart TR, Brehmer B, Steinmann DO (1975) Social judgment theory. In: Kaplan MF, Schwartz S (eds) Human judgment and decision processes. Academic Press, New York, pp 271-312

Hammond KR, McClelland GH, Mumpower J (1980) Human judgment and decision making: theories, methods, and procedures. Praeger Publishers, New York

Healey P (2009) The pragmatic tradition in planning thought. J Plan Educ Res 28(3):277-292. doi:10.1177/0739456x08325175

Heider F (1920) Zur Subjektivität der Sinnesqualitäten [On the subjectivity of sense qualities] Unpublished doctoral dissertation. University of Graz, Austria

Heider-Rosch ER (1971) Focal color areas and development of color names. Dev Psychol 4(3):447-455

Hertwig R, Bond CF (2011) Why do lie-catchers fail? A lens model meta-analysis of human lie judgment. Psychol Bull 137(4):643-659. doi:10.1037/a0023589

Hilborn RC (2004) Sea, gulls, butterflies, and grasshoppers: a brief history of the butterfly effect in nonlinear dynamics. Am J Phys 72(4):425-427. doi:10.1119/1.1636492

Hilgard ER (1955) Discussion of probabilistic functionalism. Psychol Rev 62(3):226-229. doi:10.1037/h0040825

Hogarth RM, Makridakis S (1981) Forecasting and planning-an evaluation. Manag Sci 27(2):115-138. doi:10.1287/mnsc.27.2. 115

Hölldobler B, Wilson EO (2009) The superorganism: the beauty, elegance, and strangeness of insect societies. WW Norton \& Company, New York

Hollenbeck JR, Ilgen DR, Sego DJ, Hedlund J, Major DA, Phillips JR (1995) Multilevel theory of team decision making: decision performance in teams incorporating distributed expertise. J Appl Psychol 80(2):292

Huber A (2014) Egon Brunswick (Brunswik) Gedenkbuch für die Opfer des Nationalsozialismus an der Universität Wien 1938. Universität Wien, Wien

Hulburt EM (2002) The four principles of adaptation. Ecol Model 156(1):61-84

Hull CL (1934) The concept of the habit-family hierarchy and maze learning. Psychol Rev 41(3353):134-142

Hursch CJ, Hammond KR, Hursch JL (1964) Some methodological considerations in multiple-cue probability studies. Psychol Rev 71(1):42-60. doi:10.1037/h0041729

Hutson SR, Stanton TW (2007) Cultural logic and practical reason: the structure of discard in ancient Maya houselots. Camb Archaeol J 17(2):123-144. doi:10.1017/s0959774307000212

Islam S, Susskind LE (2012) Water diplomacy: a negotiated approach to managing complex water networks. Routledge, New York

Jost J (2004) External and internal complexity of complex adaptive systems. Theory Biosci 123(1):69-88

Karayiannis N, Venetsanopoulos AN (2013) Artificial neural networks: learning algorithms, performance evaluation, and applications, vol 209. Springer, Berlin

Karelaia N, Hogarth RM (2008) Determinants of linear judgment: a meta-analysis of lens model studies. Psychol Bull 134(3):404-426. doi:10.1037/0033-2909.134.3.404

Karl F (2012) A free energy principle for biological systems. Entropy 14(11):2100-2121

Kaufmann E, Athanasou JA (2009) A meta-analysis of judgment achievement as defined by the lens model equation. Swiss $\mathrm{J}$ Psychol 68(2):99-112. doi:10.1024/1421-0185.68.2.99
Kaufmann E, Wittmann WW (2016) The success of linear bootstrapping models: decision domain-, expertise-, and criterion-specific meta-analysis. PLoS ONE 11(6):21. doi:10.1371/journal.pone. 0157914

Kay P, Regier T (2007) Color naming universals: the case of Berinmo. Cognition 102(2):289-298. doi:10.1016/j.cognition. 2005.12.008

Kirlik A (2006a) Cognitive engineering: Toward a workable concept of mind. In: Kirlik A (ed) Adaptive Perspectives on humantechnology interaction: methods and models for cognitive engineering and human-computer interaction. Oxford University Press, Oxford, p 1

Kirlik A (ed) (2006b) Adaptive perspectives on human-technology interaction. Methods and models for cognitive engineering and human-computer interaction. Oxford University Press, Oxford

Kleeb U, Heller M (1997) Blumenwiese zwischen Wahrnehmung und Wirklichkeit. Eine Installation in 14 Bildern [Flower fields between perception and reality. A setup in 14 pictures]. Museum für Gestaltung, Zurich

Komatsu H (2006) The neural mechanisms of perceptual filling-in. Nat Rev Neurosci 7(3):220

Konorski J (1967) Integrative activity of the brain. An interdisciplinary approach. University of Chicago Press, Chicago

Kozma R, Freeman WJ, Wong D, Erdi P (2004) Learning environmental clues in the KIV model of the cortico-hippocampal formation. Neurocomputing 58:721-728. doi:10.1016/j.neucom. 2004.01.119

Laws D, Scholz RW, Shiroyama H, Susskind L, Suzuki T, Weber O (2004) Expert views on sustainability and technology implementation. Int J Sustain Dev World Ecol 11(3):247-261

Lettvin JY, Maturana HR, McCulloch WS, Pitts WH (1959) What the frog's eye tells the frog's brain. Proc IRE 47(11):1940-1951

Levin J (2013) Functionalism. In: Zalta EN (ed) The Stanford encyclopedia of philosophy. The Metaphysics Research Lab, Center for the Study of Language and Information (CSLI), Stanford University, Stanford

Linkov I, Cormier S, Gold J, Satterstrom FK, Bridges T (2012) Using our brains to develop better policy. Risk Anal 32(3):374-380

Liu J, Dietz T, Carpenter SR, Alberti M, Folke C, Moran E et al (2007a) Complexity of coupled human and natural systems. Science 317(5844):1513

Liu JG, Dietz T, Carpenter SR, Folke C, Alberti M, Redman CL et al (2007b) Coupled human and natural systems. Ambio 36(8):639-649

Loukopoulos P, Scholz RW (2004) Sustainable future urban mobility: using 'area development negotiations' for scenario assessment and participatory strategic planning. Environ Plan A 36(12):2203-2226

Lovelock JE (1995) Gaia. Oxford University Press, Oxford

Martin L (1986) Eskimo words for snow-a case-study in the genesis and decay of an anthropological example. Am Anthropol 88(2):418-423. doi:10.1525/aa.1986.88.2.02a00080

Masland RH (2001) The fundamental plan of the retina. Nat Neurosci 4(9):877-886

Mayr E (1998) Prologue: some thoughts on the history. In: Mayr E (ed) The evolutionary synthesis: perspectives on the unification of biology, 2nd edn. Cambridge, pp 1

McBride MF, Garnett ST, Szabo JK, Burbidge AH, Butchart SH, Christidis L et al (2012) Structured elicitation of expert judgments for threatened species assessment: a case study on a continental scale using email. Methods Ecol Evol 3(5):906-920

McDaniels T, Wilmot S, Healey M, Hinch S (2010) Vulnerability of Fraser River sockeye salmon to climate change: a life cycle perspective using expert judgments. J Environ Manag 91(12):2771-2780 
McMahon DBT, Jones AP, Bondar IV, Leopold DA (2014) Faceselective neurons maintain consistent visual responses across months. Proc Natl Acad Sci 111(22):8251-8256

Meehl P (1954) Clinical versus statistical prediction: a theoretical analysis and a review of the evidence. University of Minnesota Press, Minneapolis

Minsky M (1963) Steps toward artificial intelligence. In: Feigenbaum AE, Feldman J (eds) Computers and thought. McGraw-Hill, New York, pp 102-154

Mori K, Christodoulou A (2012) Review of sustainability indices and indicators: towards a new City Sustainability Index (CSI). Environ Impact Assess Rev 32(1):94-106

Morse S (2015) Developing sustainability indicators and indices. Sustain Dev 23(2):84-95

Mossman K (2014) The complexity paradox: the more answers we find, the more questions we have. Oxford University Press, Oxford

Moutoussis K, Zeki S (2002) The relationship between cortical activation and perception investigated with invisible stimuli. Proc Natl Acad Sci 99(14):9527-9532

Mumpower JL (2001) Brunswikian research ond social perception, interpersonal learning, and conflict, and negotiation. In: Hammond KR, Stewart TR (eds) The Essential Brunswik: beginnings, explication, applications. Oxford University Press, Oxford, pp 388-393

National Research Council (2015) Developing a framework for measuring community resilience: summary of a workshop. National Academies Press, Washington, DC

Radler J (2015) Bringing the environment in: Early Central European contributions to an ecologically Oriented psychology of perception. Hist Psychol 18(4):401-413. doi:10.1037/a0039059

Reed MS, Graves A, Dandy N, Posthumus H, Hubacek K, Morris J et al (2009) Who's in and why? A typology of stakeholder analysis methods for natural resource management. J Environ Manag 90(5):1933-1949. doi:10.1016/j.jenvman.2009.01.001

Rohrbaugh J (1979) Improving the quality of group judgment: social judgment analysis and the Delphi technique. Organ Behav Hum Perform 24(1):73-92

Rosenblatt F (1958) The perceptron-a probabilistic model for information-storage and organization in the brain. Psychol Rev 65(6):386-408. doi:10.1037/h0042519

Rosenblatt F (1961) Principles of neurodynamics. Perceptrons and the theory of brain mechanisms. Retrieved from Buffalo

Roth G, Dicke U (2005) Evolution of the brain and intelligence. Trends Cognit Sci 9(5):250-257

Saaty TL (1990) The analytic hierarchy process, 2nd edn. RWS Publications, Pittsburgh

Schiller PH, Logothetis NK, Charles ER (1990) Functions of the colour-opponent and broad-band channels of the visual system. Nature 343(6253):68

Scholz RW (1987) Cognitive strategies in stochastic thinking. Reidel, Dordrecht

Scholz RW (2011) Environmental literacy in science and society: from knowledge to decisions. Cambridge University Press, Cambridge

Scholz RW (2017a) Digital threat and vulnerability management: the SVIDT method. Sustainability 9(4):554

Scholz RW, Stauffacher M (2007) Managing transition in clusters: area development negotiations as a tool for sustaining traditional industries in a Swiss prealpine region. Environ Plan A 39(10):2518-2539

Scholz RW, Stauffacher M (2010) The transdisciplinarity laboratory at the ETH Zurich: fostering reflection-in-action in higher education. Plan Theory Pract 11(2):606-609
Scholz RW, Steiner G (2015a) The real type and the ideal type of transdisciplinary processes. Part I-theoretical foundations. Sustain Sci 10(4):527-544. doi:10.1007/s11625-015-0326-4

Scholz RW, Steiner G (2015b) The real type and the ideal type of transdisciplinary processes. Part II-what constraints and obstacles do we meet in practice? Sustain Sci 10(4):653-671. doi:10. 1007/s11625-015-0327-3

Scholz RW, Tietje O (1996) Methoden der Fallstudie. In: Scholz RW, Bösch S, Koller T, Mieg HA, Stünzi J (eds) Industrieareal Sulzer-Escher Wyss: Umwelt und Bauen-Wertschöpfung durch Umnutzung (ETH-UNS Fallstudie 1995). Vdf, Zürich, pp 31-70

Scholz RW, Tietje O (2002) Embedded case study methods: Integrating quantitative and qualitative knowledge. Sage, Thousand Oaks

Scholz RW, Bösch S, Koller T, Mieg HA, Stünzi J (eds) (1996) Industrieareal Sulzer-Escher Wyss: Umwelt und BauenWertschöpfung durch Umnutzung (ETH-UNS Fallstudie 1995) [Industrial area Sulzer-Escher Wyss: environment and construction-value added through re-use (ETH-UNS case study 1995)]. Vdf, Zurich

Scholz RW, Tietje O, Stünzi J, Heitzer A (1997) Methods of environmental problem solving and of knowledge integration in case studies. In: Vezjak M, Stuhler EA, Muley M (eds) Environmental problem solving: from cases and experiments to concepts, knowledge, tools and motivation. Hampp, München, pp 211-216

Scholz RW, Lang DJ, Wiek A, Walter AI, Stauffacher M (2006) Transdisciplinary case studies as a means of sustainability learning: historical framework and theory. Int J Sustain High Educ 7(3):226-251

Scholz RW, Stauffacher M, Bösch S, Krütli P, Wiek A (eds) (2007) Entscheidungsprozesse Wellenberg-Lagerung radioaktiver Abfälle in der Schweiz (ETH-UNS Fallstudie 2006) [Decision processess Wellenberg-Repository of radioactive waste in Switzerland (ETH-UNS Case Study 2006)]. Rüegger, Zurich

Scholz RW, Blumer YB, Brand FS (2012) Risk, vulnerability, robustness, and resilience from a decision-theoretic perspective. J Risk Res 15(3):313-330. doi:10.1080/13669877.2011.634522

Scholz RW, Roy AH, Brand FS, Hellums DT, Ulrich AE (eds) (2014) Sustainable phosphorus management: a global transdisciplinary roadmap. Springer, Berlin

Schori S, Krütli M, Stauffacher M, Flüeler T, Scholz RW (2009) Siting of nuclear waste repositories in Switzerland and Sweden. Stakeholder preferences for the interplay between technical expertise and social input. ETH-NSSI Case Study 2008. Retrieved from Zurich

Seidl R, Brand F, Stauffacher M, Krütli P, Le QB, Spörri A et al (2013) Science with society in the anthropocene. Ambio 42(1):5-12

Slovic P, Fischhoff B, Lichtenstein S (1977) Behavioral decision theory. Annu Rev Psychol 28(1):1-39

Snowden R, Snowden RJ, Thompson P, Troscianko T (2012) Basic vision: an introduction to visual perception. Oxford University Press, Oxford

Sperling G (1963) A model for visual memory tasks. Hum Factors 5(1):19-31

Stauffacher M, Scholz RW (2013) HES-based transdisciplinary case studies: the example of sustainable transformation of leisure traffic in the city of Basel. In: Mieg HA, Töpfer K (eds) Institutional and social innovation for sustainable urban development. Routledge, London, pp 25-43

Street P (1997) Scenario workshops: a participatory approach to sustainable urban living? Futures 29(2):139-158

Susskind LE, McKearnan S, Thomas-Larmer J (2000) The consensus building handbook. Sage, Thousand Oaks 
Swenk J (1999) Planning failures: decision cultural clashes. Rev High Educ 23(1):1-21

The Brunswikian Society (2015) Complete bibliography of the publications of Egon Brunswik. Retrieved from http://www. brunswik.org/resources/brunswikrefs.html

Tietje $\mathrm{O}$ (2005) Identification of a small reliable and efficient set of consistent scenarios. Eur J Oper Res 162(2):418-432

Tolman EC (1933) Purposive behavior in animals and men. Century, New York

Tolman EC (1956) Brunswik, Egon-1903-1955. Am J Psychol 69(2):315-324

Tolman EC, Brunswik E (1935) The organism and the causal texture of the environment. Psychol Rev 42(1):43-77

Tolman CW, Postman BFR, Ritchie BF (1958) University of California: in memoriam. Egon Brunswik, psychology: Berkeley, 1903-1955. The Regents of The University of California, Academic Senate, Berkeley, pp 18-21

Tourki Y, Keisler J, Linkov I (2013) Scenario analysis: a review of methods and applications for engineering and environmental systems. Environ Syst Decis 33(1):3-20. doi:10.1007/s10669013-9437-6

Tversky A, Kahneman D (1974) Judgment under uncertainty: heuristics and biases. Science 185:1124-1131

Uebel T (2011) Vienna circle. In: Lab TMR (ed) Stanford encyclopedia of philosophy

UN (2016) Sustainable development goals. Guidelines for the use of the SDG logo, including the colour wheel, and 17 icons. In U. Nations (ed) United Nations Department of Public Information

van Breda J (2014). Personal communication (see for the case: Enkanini Informal Settlement) von Uexküll $\mathrm{T}$ (1987) The sign theory of Jakob von Uexküll. In: Krampen M, Oehler K, Posner R, Sebeok TA, von Uexküll T (eds) Classics of semiotics. Plenum Press, New York, pp 147-179

Merriam Webster (ed) (2017) Webster's third new international dictionary, unabridged. Merriam Webster, Springfield

Whorf B (1956) Language, thought and reality. University of California Press, Berkeley

Wilson EO, Nowak MA (2014) Natural selection drives the evolution of ant life cycles. Proc Natl Acad Sci 111(35):12585-12590

Wilson DS, Sober E (1989) Reviving the superorganism. J Theor Biol 136(3):337-356

Wilson DS, Sober E (1994) Reintroducing group selection to the human behavioral-sciences. Behav Brain Sci 17(4):585-608

Wilson DS, Sober E (1996) More on group selection and human behavior. Behav Brain Sci 19(4):782-787

Wilson DS, Sober E (1998) Multilevel selection and the return of group-level functionalism-response. Behav Brain Sci 21(2):305-306. doi:10.1017/s0140525x 98221194

Wilson DS, Wilson EO (2007) Rethinking the theoretical foundation of sociobiology. Q Rev Biol 82(4):327-348

Wolf B (1995) Brunswik und ökologische Perspektiven in der Psychologie. Deutscher Studien Verlag, Weinheim

Yuodelis C, Hendrickson A (1986) A qualitative and quantitative analysis of the human fovea during development. Vis Res $26: 847-856$

Zimbardo PG, Johnson RL, Weber AL (2005) Psychology: core concepts, 5th edn. Pearson, Boston 